\title{
Variable $\mathrm{Ni}$ isotope fractionation between Fe-oxyhydroxides and implications for the use of $\mathrm{Ni}$ isotopes as geochemical tracers
}

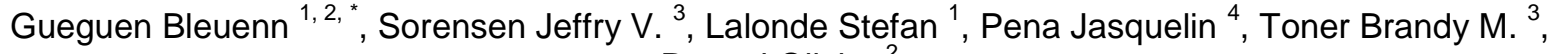 \\ Rouxel Olivier ${ }^{2}$
}

${ }^{1}$ Univ Brest, Lab Geosci Ocean, Inst Univ Europeen Mer, UMR 6538, F-29280 Plouzane, France.

2 IFREMER, Ctr Brest, Unite Geosci Marines, F-29280 Plouzane, France.

${ }^{3}$ Univ Minnesota, Dept Soil Water \& Climate, St Paul, MN 55108 USA.

${ }^{4}$ Univ Lausanne, Inst Earth Surface Dynam, $\mathrm{CH}-1015$ Lausanne, Switzerland.

* Corresponding author : Bleuenn Gueguen, email address : bleuenn.gueguen@univ-brest.fr

\begin{abstract}
:
Nickel (Ni) isotopes have recently emerged as a new biogeochemical tracer in marine environments, but our understanding of the mechanisms of $\mathrm{Ni}$ isotope fractionation in natural systems with regards to its fractionation by mineral surfaces is incomplete. This study aims to provide experimental constraints on $\mathrm{Ni}$ isotope fractionation during adsorption to goethite and 2-line ferrihydrite, two Fe minerals that vary in terms of distinct crystalline properties. We conducted two types of adsorption experiments: one with variable pH (5.0 to 8.0) and constant initial $\mathrm{Ni}$ concentration, one at a constant $\mathrm{pH}$ of 7.7 and variable initial Ni concentrations. Isotopic measurements were made on both the solid phase and the supernatant solutions in order to determine the $\mathrm{Ni}$ isotope fractionation factors $(\Delta 60 / 58 \mathrm{Nimin}$-aq $=\delta 60 / 58 \mathrm{Nimin}-\delta 60 / 58 \mathrm{Niaq})$ between the mineral and aqueous phases. Our results show preferential adsorption of lighter $\mathrm{Ni}$ isotopes during adsorption of $\mathrm{Ni}$ to $\mathrm{Fe}$ oxyhydroxides presumably under conditions of near equilibrium conditions. Adsorption to goethite generates the greatest fractionation, with $\Delta 60 / 58 \mathrm{Nimin}$-aq $=-0.77 \pm 0.23 \%$ o $(n=14,2 \mathrm{sd})$, whereas adsorption to 2-line ferrihydrite samples yield $\Delta 60 / 58 \mathrm{Nimin}$-aq $=-0.35 \pm 0.08 \%$ o $(n=16,2 \mathrm{sd})$. Using Ni K-edge extended X-ray absorption fine structure (EXAFS) spectroscopy, we found that Ni forms an inner-sphere complex and that its coordination environment does not vary significantly with $\mathrm{pH}$ nor with surface loading. In addition, we found no evidence of $\mathrm{Ni}$ incorporation into the mineral. We suggest that the more than two-fold increase in $\mathrm{Ni}$ isotope fractionation in goethite relative to 2-line ferrihydrite is due to the lower $\mathrm{Ni}$-Fe coordination number in the second shell, which results in the formation of a weaker surface complex and thus favors the adsorption of lighter $\mathrm{Ni}$ isotopes. These results show that $\mathrm{Ni}$ isotope fractionation during sorption by Fe-oxyhydroxides is dependent on mineralogy, which has important implications for the use of $\mathrm{Ni}$ isotopes as environmental tracers and the interpretation of their record in sedimentary rocks.
\end{abstract}

Keywords : Fe-oxyhydroxides, Sorption experiments, Nickel isotopes 


\section{Introduction}

Nickel is a micro-nutrient in modern oceans and displays a nutrient-type profile in seawater, where it is depleted in surface waters due to biological uptake (Bruland, 1980; Price and Morel, 1991; Morel and Price, 2003). The evolution of marine biogeochemical Ni cycling has become a topic of much interest as ancient metalliferous deposits because Banded Iron Formations (BIF) appear to record a dramatic decrease in marine Ni concentrations through geological time (Konhauser et al., 2009; Konhauser et al., 2015), attributed to a shift from ultramafic volcanism and eruption of Ni-rich komatiites to basaltic volcanism as the Earth's crust cooled. Iron-rich sedimentary rocks such as Granular Iron Formations (GIF) and BIF were deposited from seawater throughout much of the Precambrian and have been widely used as an archive to reconstruct the geochemical composition of seawater in Precambrian marine environments, in which Fe-oxyhydroxides were the carriers of trace metals (e.g., Bekker et al., 2010). Hence, Ni isotope systematics of Iron Formations hold great promise for the study of ancient biogeochemical cycles and paleo-environments. But first, the mechanisms of $\mathrm{Ni}$ isotope fractionation during Fe-oxyhydroxide precipitation and burial need to be well constrained.

The geochemical cycling of $\mathrm{Ni}$ in modern oceans is largely controlled by input from continental weathering and riverine transport and removal from seawater through precipitation in authigenic Mn-rich sediments (Sclater et al., 1976; Gall et al., 2013; Cameron and Vance, 2014). Preliminary investigations have shown that seawater is characterized by an average $\delta^{60 / 58} \mathrm{Ni}$ value of $1.44 \pm 0.15 \%$ ( $(2 \mathrm{sd}, \mathrm{n}=29)$ relative to the NIST SRM 986 international standard, which is heavier than the average crustal value (estimated at 0.05 $\pm 0.05 \%$; Gueguen et al., 2013). The riverine input flux is estimated at a $\delta^{60 / 58} \mathrm{Ni}$ value of 
$0.80 \%$ with a range of values from $0.29 \%$ to $1.34 \%$ (Cameron and Vance, 2014). The oceanic output flux, dominated by authigenic Mn-oxyhydroxides (Krishnaswami, 1976; Leinen, 1987; Koschinsky and Halbach, 1995; Manceau et al., 2002; Peacock and Sherman, $2007 \mathrm{~b}$ ), has a $\delta^{60 / 58} \mathrm{Ni}$ value of $\sim 1.7 \%$ (i.e., the average $\mathrm{Ni}$ isotope composition of hydrogenetic ferromanganese crusts as reported by Gall et al. (2013) and Gueguen et al. (2016)). The isotopically heavy signature of rivers relative to the bulk crust implies that a light $\mathrm{Ni}$ isotopic reservoir should be retained in the continental crust, probably during soil formation (Ratié et al., 2015). Based on isotopic mass balance considerations, Cameron and Vance (2014) identified a missing source of isotopically heavy Ni in modern oceans.

Alternatively, the heavy $\mathrm{Ni}$ isotopic composition of seawater could be balanced by an oceanic sink enriched in light Ni isotopes, perhaps in sulfides (Gueguen et al., 2013; Hofmann et al., 2014) associated with anoxic or suboxic marine sediments enriched in organic matter that accumulate in reducing environments (e.g., continental margins with strong upwelling regimes, restricted anoxic basins, fjords). However, the role of organic-rich sediments in the $\mathrm{Ni}$ isotope mass balance is unclear as bulk $\delta^{60 / 58} \mathrm{Ni}$ of organic-rich sediments display a large range from $0.28 \%$ to $2.5 \%$ (Porter et al., 2014).

Large terrestrial Ni reservoirs exist in ultramafic complexes (Manceau and Calas, 1985; Valeton et al., 1987; Butt and Cluzel, 2013), and weathering of these complexes can lead to significant $\mathrm{Ni}$ enrichment in laterites. While Ni released during weathering of ultramafic complexes will have a greater affinity for Mn-oxides (Manceau et al., 1987), a significant portion of $\mathrm{Ni}$ is in fact sequestered in the abundant Fe-oxides (mostly goethite) formed during lateritization (Manceau et al., 2000; Quantin et al., 2008; Dublet et al., 2012; Dublet et al., 2014; Ratié et al., 2015). In a recent study, Ratié et al. (2015) demonstrated that weathering of ultramafic complexes leads to the enrichment of light $\mathrm{Ni}$ isotopes (by $-0.47 \%$ ) in Ni-rich laterites relative to unweathered bedrock, consistent with the preferential loss of 
heavy $\mathrm{Ni}$ isotopes to the mobile phase and eventually to the riverine flux. Nickel in these laterites is either incorporated into the mineral lattice or sorbed onto the mineral surface. Nickel sorption on Fe-oxyhydroxides may therefore influence the isotope signature of $\mathrm{Ni}$ in weathering environments, and in turn, the riverine flux of $\mathrm{Ni}$ to the oceans.

The use of $\mathrm{Ni}$ isotopes as biosignatures has also garnered attention in the recent literature and the evolution of Ni biogeochemical cycling in the ancient oceans may be recorded in the Ni isotope composition of coeval authigenic sediments. However, understanding the isotope fractionation of metals such as $\mathrm{Ni}$ during adsorption to $\mathrm{Fe}$-oxides and other authigenic minerals is paramount to accurately reconstruct the biogeochemical cycling of nutrients using the sedimentary record. Wasylenki et al. (2015) reported the equilibrium $\mathrm{Ni}$ isotope fractionation factor during $\mathrm{Ni}$ sorption to ferrihydrite (experiments done at room temperature), showing an enrichment of the light $\mathrm{Ni}$ isotopes on the solid phase by $-0.35 \pm 0.10 \%$ o $(1 \mathrm{sd})$. However, further studies are needed in order to evaluate in more detail the mechanisms and range of parameters controlling $\mathrm{Ni}$ isotope fractionation during adsorption onto mineral phases, including the effects of coordination environment or the type of mineral phase (e.g., poorly crystalline versus more crystalline phases). For instance, different $\mathrm{Ni}$ isotope fractionation could be expected among different Fe-oxyhydroxides based on coordination chemistry considerations, because this effect has been observed for other metal/metalloid isotope systems such as $\mathrm{Cu}, \mathrm{Ge}$, Mo and Zn (Pokrovsky et al., 2008; Li and Liu, 2010; Wasylenki et al., 2011; Pokrovsky et al., 2014). These experimental data are crucial to interpret the trace metal isotopic records in Iron Formations, where the mechanism of formation of Fe-oxyhydroxides- precursor mineral phases and scavenging of trace metals are poorly known, and to evaluate the preservation of the isotopic signal during recrystallization. The role of iron oxides recrystallization on the Ni cycling is also important 
to consider as it could have impacted the Ni signal preserved in Iron Formations (Frierdich et al., 2011).

To address this problem, we conducted $\mathrm{Ni}$ adsorption experiments on two synthetic Fe-oxyhydroxides, 2-line ferrihydrite and goethite, as a function of $\mathrm{pH}$, variable Ni loading to pre-formed minerals, (i.e., no co-precipitation) and duration of experiments. Our goal is to mechanistically understand the isotope fractionation during $\mathrm{Ni}$ adsorption to Fe-phases with different crystallinity, with special consideration to Ni speciation, coordination, and structure of adsorbent. The local coordination environment of $\mathrm{Ni}$ at the mineral surface was evaluated by Ni K-edge EXAFS spectroscopy, while the isotopic fractionation of $\mathrm{Ni}$ between solid and aqueous phases were measured by Multi Collector-Inductively Coupled Plasma-Mass Spectrometer (MC-ICP-MS) using double-spike $\left({ }^{61} \mathrm{Ni}^{-62} \mathrm{Ni}\right)$ correction of instrumental mass bias. Our results build on the results of Wasylenki et al. (2015) regarding the causes for $\mathrm{Ni}$ isotope fractionation. We expand on the role of Fe-oxides in the transfer of continental $\mathrm{Ni}$ to the oceans and in the biogeochemical cycling of $\mathrm{Ni}$ isotopes, furthering the development of $\mathrm{Ni}$ isotopes as a geochemical tracer in surface environments.

\section{Materials and methods}

We used synthetic mineral phases to investigate surface driven $\mathrm{Ni}$ isotope fractionation. The use of synthetic mineral phases allowed for Ni K-edge EXAFS spectroscopy on samples with low Ni concentration without interference from significant amounts of incorporated $\mathrm{Ni}$. Goethite $(\alpha-\mathrm{FeOOH})$ and 2-line ferrihydrite were synthesized by raising the $\mathrm{pH}$ of a $\mathrm{Fe}\left(\mathrm{NO}_{3}\right)_{3}$ solution with $\mathrm{KOH}$ at $25^{\circ} \mathrm{C}$. Goethite was formed by heating the solid precipitate at $70^{\circ} \mathrm{C}$ for 60 hours following the protocol of Cornell and Schwertmann (2003). The precipitates were washed three times with ultrapure water and centrifuged at 
7,000 rpm for 30 minutes. The goethite was stored freeze-dried while the 2-line ferrihydrite was synthesized within 48 hours of each experiment and stored at $-30^{\circ} \mathrm{C}$. The synthetic minerals were characterized by BET (Brunauer-Emmett-Teller) surface area, powder X-ray diffraction, and electrophoretic mobility. For BET, samples were dried and degassed at $150^{\circ} \mathrm{C}$ before specific surface area was measured by $\mathrm{N}_{2}$ adsorption (Micromeritics Tristar II 3020). The specific surface areas for goethite and 2-line ferrihydrite were 25.5 and $119 \pm 3 \mathrm{~m}^{2} / \mathrm{g}$, respectively. Bulk powder X-ray diffraction was performed using a Pananalytical X'Pert Pro diffractometer (Characterization Facility, University of Minnesota). Mineral surface charge, which is reflected in surface electrokinetic potential, was determined using a ZetaPALS analyzer (Brookhaven Instruments Corp.) for $0.98-1.44 \mathrm{~g} / \mathrm{L}$ of mineral suspended in ultrapure water. Instrumental settings consisted of an applied voltage of $7.54 \mathrm{~V}$ and electric field of $9.29 \mathrm{~V} / \mathrm{cm}$. Data were acquired over 3 cycles of 5 measurements per mineral (Electronic Annex, Table A1).

\subsection{Nickel sorption experiments}

For the Ni sorption experiments, a stock solution of $17 \mathrm{mmol} / \mathrm{L} \mathrm{Ni}(1000 \mathrm{mg} / \mathrm{L} \mathrm{Ni})$ was made with a $\mathrm{Ni}\left(\mathrm{NO}_{3}\right)_{2} \cdot \mathrm{H}_{2} \mathrm{O}(\mathrm{aq})$ salt (Fischer Scientific). Aqueous suspensions were prepared with $0.15 \mathrm{~g}$ of goethite or 2-line ferrihydrite in $150 \mathrm{~mL}$ of $0.05 \mathrm{~mol} / \mathrm{L} \mathrm{NaNO}_{3}$ in 250 $\mathrm{mL}$ Teflon bottles. The Fe-oxyhydroxides were allowed to equilibrate for 24 hours at the target experimental $\mathrm{pH}$ before the addition of an aliquot of $\mathrm{Ni}$ from the stock solution. Nickel was added slowly using a micropipette over a 15 minutes' period, with continuous mixing with a Teflon-coated stir bar to reduce changes to the $\mathrm{pH}$ of the suspension. A control consisting of the mineral in $0.05 \mathrm{~mol} / \mathrm{L} \mathrm{NaNO}_{3}$ solution with no $\mathrm{Ni}$ added was included with each set of experiments and $\mathrm{Ni}$ in the blank did not exceed $0.1 \%$ of the total amount of $\mathrm{Ni}$ 
measured during Ni sorption experiments. Samples were named according to the adsorbent (i.e., "Fh" for 2-line ferrihydrite and "Goe" for goethite) and the type of experiment (i.e., “pH" for $\mathrm{pH}$-dependent experiments, "C" for varying initial $\mathrm{Ni}$ concentration experiments and “T” for time-dependent experiments).

Nickel sorption experiments (Table 1) were performed as a function of $\mathrm{pH}(\mathrm{pH} 5.0$, 6.0, 7.0, 7.7 and 8.0) with an initial Ni concentration of $170 \mu \mathrm{mol} / \mathrm{L} \mathrm{Ni}(10 \mathrm{mg} / \mathrm{L} \mathrm{Ni}) . \mathrm{A}$ separate set of $\mathrm{Ni}$ sorption experiments were also performed at $\mathrm{pH} 7.7$ as a function of initial Ni concentration $(17,85,170,341$, and $426 \mu \mathrm{mol} / \mathrm{L} \mathrm{Ni})$. The suspension $\mathrm{pH}$ was maintained constant within $\pm 0.2 \mathrm{pH}$ units with a custom-built $\mathrm{pH}$ control system consisting of 6 Hanna Instruments HI 504 controllers, each equipped with a Thermo Scientific Orion 9110 pH electrode. Adjustments of the $\mathrm{pH}$ were made with additions of $0.05 \mathrm{~mol} / \mathrm{L} \mathrm{HCl}$ and 0.05 mol/L NaOH using two 3-way General Valve ${ }^{\mathrm{TM}}$ solenoid valves and a Manostat Carter peristaltic cassette pump. The $\mathrm{pH}$ electrodes were calibrated using $\mathrm{pH} 4$ and $\mathrm{pH} 7$ commercial buffers before each experiment. After the addition of $\mathrm{Ni}$, the suspension was allowed to react for 24 hours before the solution was separated from the solids by vacuum filtration $(0.22 \mu \mathrm{m}$ polycarbonate filter, Millipore). The solids were not rinsed prior to storage or analysis. After filtration, the supernatant solution was refrigerated at $2^{\circ} \mathrm{C}$ until analysis by ICP-MS and the solid material on filter was stored at $-20^{\circ} \mathrm{C}$. The solid-phase samples on the filter membranes were cut in half and reserved for Ni K-edge EXAFS spectroscopy and isotopic analysis.

Time-dependent experiments were done to check whether kinetic isotopic effects are affecting our experiments (Table 2). They were performed at a fixed $\mathrm{pH}$ of 7.7 and at two different initial $\mathrm{Ni}$ concentrations of $170 \mu \mathrm{mol} / \mathrm{L}$ and $426 \mu \mathrm{mol} / \mathrm{L}$, in order to assess the potential effect of dissolved Ni concentration (i.e., Ni loading) on Ni isotope fractionation factor. Four different batches were prepared for each initial Ni concentration and were allowed to react for 18 (or 19 hours for 2-line ferrihydrite), 20, 22, and 23 hours, respectively. 
A maximum equilibration time of 24 hours was chosen based on our initial test timedependent experiments with goethite and ferrihydrite in which the aqueous Ni concentration stabilized after 18 to 23 hours of reaction, consistent with experimental design implemented by Wasylenki et al. (2015). These findings are consistent with bulk chemical equilibrium and were used to choose the reaction time for the adsorption experiments. This also prevents the potential effect of diffusion-controlled penetration of $\mathrm{Ni}$ into $\mathrm{Fe}$ (oxy)hydroxides on $\mathrm{Ni}$ isotope fractionation, since this process has been shown to occur over long (week to month) timescales, while surface adsorption reaches completion within a few hours (Bruemmer et al., 1988). As discussed below, at bulk chemical equilibrium the mineral continues to exchange $\mathrm{Ni}$ with the aqueous phase, so isotopic changes are still possible. By contrast, no net change in loading to the mineral occurs, implying that the Ni concentration in the mineral is constant.

\subsection{Nickel K-edge EXAFS spectroscopy}

Nickel K-edge EXAFS spectroscopy measurements were conducted at the Advanced Photon Source (Argonne National Laboratory) at beamline 20-BM in fluorescence mode using a 12-element Canberra germanium detector. The Ni-sorbed minerals were prepared for Ni K-edge EXAFS analysis by thawing to room temperature and transferring from the filter to a mylar adhesive with a microspatula. Multiple mylar layers were stacked (6-8 layers) and the edges sealed to form an envelope around the sample. Measurements were conducted at room temperature and individual scans were examined for systematic changes in peak-position or shape to detect photon-induced sample alteration; none was observed. Multiple scans were averaged to improve the signal to noise ratio. The Athena program was used for averaging replicate scans and energy calibration ( $\mathrm{Ni}$ foil with inflection point set to $8334.5 \mathrm{eV}$ ), and the Artemis program was used to generate phase and amplitude paths for Ni K-edge EXAFS 
fitting (Ravel and Newville, 2005). Data reduction, including background subtraction and conversion to k-space, and shell-by-shell fitting were performed using the SixPack software package (Webb, 2005) with the following settings: $\mathrm{E}_{0}=8347 \mathrm{eV}, \mathrm{R} b k g=1.0 \AA$ (Kelly et al., 2008), a Gaussian pre-edge function, quadratic post-edge function, no clamping, default spline knots value, a Kaiser-Bessel window function, and a $k$-weight $=3$. The amplitude reduction factor, $\mathrm{S}_{0}^{2}=0.96$, was determined by fitting the first coordination shell of aqueous published standards ( $\mathrm{NiCl}_{2}$ and Ni-EDTA) (Peña et al., 2010). Fits were evaluated using the calculated R-factor with a value of 0.05 or less representing a reasonable fit (Kelly et al., 2008).

X-ray absorption spectra were collected from 8130 to $9300 \mathrm{eV}$. Models for the adsorption geometry of $\mathrm{Ni}$ were based on the assumption that $\mathrm{Ni}$ coordinates to Fe octahedra via edge-sharing or corner-sharing linkages. First, the Ni-O shell was fit with all parameters varied. The optimized parameters for the first shell were constrained in subsequent fits, which included second-shell Ni-Fe paths.

The Ni-Fe second shell was modeled assuming to the occurrence of short and long bond distances, following the model used for Ni/Zn sorption on ferrihydrite (Arai, 2008; Cismasu et al., 2013). Specifically, two types of bond orientations between $\mathrm{Fe}$ and $\mathrm{Ni}$ octahedral were modeled. Type 1 is comprised of a Ni octahedron that shares an edge, two bond via two shared oxygen molecules, with an Fe octahedra (mineral surface). Type 2 is comprised of a $\mathrm{Ni}$ octahedron that shares a corner, or one bond via a shared oxygen, with an Fe octahedra (mineral surface). Type 1 bond distances are shorter and share more bonds with the mineral surface than Type 2. Distortion of the Ni-O coordination sphere can be influenced by either the number of bonds with the mineral surface, or geometric strain introduced due to the type of surface site (e.g., number/type of Fe octahedra) to which the Ni binds. 
The Ni K-edge EXAFS model was based on published coordination number $(\mathrm{CN})$

ratios of a short and long $\mathrm{Ni}-\mathrm{Fe}$ and $\mathrm{Zn}-\mathrm{Fe}$ paths in the second shell of $\mathrm{Ni} \mathrm{K}$-edge EXAFS data from Ni/Zn-adsorbed 2-line ferrihydrite samples (Table 3) (Manceau and Gates, 1997;

Carvalho-E-Silva et al., 2003; Arai, 2008; Dublet et al., 2012; Cismasu et al., 2013). Reported $\mathrm{CN}$ ratios for Ni-sorbed 2-line ferrihydrite ranged from $0.4: 0.7\left(\mathrm{CN}_{\text {short }}: \mathrm{CN}_{\text {long }}\right)$ with a maximum total second-shell $\mathrm{CN}$ of 5 (Arai, 2008). Thus, $\mathrm{CN}_{\text {short }}: \mathrm{CN}_{\text {long }}$ ratios of $1: 1$ to $4: 5$ were tested in the model. A ratio of 2:3 best described the Ni K-edge EXAFS data in both fit statistics and uncertainty of varied parameters. In the final model, two type $1 \mathrm{Ni}-\mathrm{Fe}$ paths were modeled for every three type $2 \mathrm{Ni}-\mathrm{Fe}$ paths. The uncertainties on the $\mathrm{CN}$ values are between 0.144 and 0.931 (estimated to be $\sim 25 \%$ of the $\mathrm{CN}$ value) and the uncertainties on the interatomic distances are between 0.0078 and $0.0618 \AA$.

\subsection{Aqueous speciation of $\mathrm{Ni}$}

The aqueous speciation of $\mathrm{Ni}$ was calculated for the initial experimental conditions using the MINEQL+ v.4.6 software program (Environmental Research Softaware) with default stability constants. The calculations used the initial Ni concentrations $(17,85,170$, 341 , and $426 \mu \mathrm{mol} \mathrm{Ni} / \mathrm{L}), \mathrm{pH}$ range (5.0 to 8.0 in 20 steps), ionic strength $(0.05 \mathrm{~mol} / \mathrm{L}$ $\left.\mathrm{NaNO}_{3}\right)$, and partial pressure of $\mathrm{CO}_{2} \mathrm{~g}(0.03943 \mathrm{vol} \%)$ for a system in contact with the atmosphere and showed that no Ni precipitation is predicted for our experimental conditions.

We used Ni surface complexation values for bidentate adsorption on goethite $\left[2=\mathrm{SOH}+\mathrm{Ni}^{2+}\right.$ $\left.\Leftrightarrow=2(\mathrm{SOH}) \mathrm{Ni}+2 \mathrm{H}^{+}, \log \mathrm{K}=-2.45\right]$ from Xu et al. (2006), and for ferrihydrite, monodentate adsorption per Dzombak and Morel (1990) (their classic two-site ferrihydrite model, strong and weak sites, as already included in vMINTEQ). For aqueous speciation calculations during adsorption modeling, the default vMINTEQ thermo.vdb database was used, which is an 
expanded version of the MINTEQA2 database. Between $\mathrm{pH} 5.0$ and 7.0, the dominant Ni species in aqueous solution, under the initial experimental conditions considered here, is the $\mathrm{Ni}^{2+}$ (hexaquo) $(>88 \%)$. In addition to $\mathrm{Ni}^{2+}$ (hexaquo), $\mathrm{NiNO}_{3}{ }^{+}$is present and accounts for $>$ $11 \%$ of the $\mathrm{Ni}$ in solution. For the experiments with a $\mathrm{pH}$ value greater than 7.0 , the aqueous $\mathrm{Ni}$ species include minor contributions from $\mathrm{NiHCO}_{3}{ }^{+}$and $\mathrm{NiCO}_{3}{ }^{0}$. Slow addition of $\mathrm{Ni}$ during the experiments over a 15-minutes period reduced the risk of precipitation of $\mathrm{Ni}$ above $\mathrm{pH}$ 7.8. For the experiments at $\mathrm{pH} 7.7, \mathrm{Ni}$ occurs as: (1) $83.7 \% \mathrm{Ni}^{2+}$ (hexaquo); (2) $10.7 \%$ $\mathrm{NiNO}_{3}{ }^{+}$; (3) $4.1 \% \mathrm{NiHCO}_{3}{ }^{+}$; and (4) $1.5 \% \mathrm{NiCO}_{3}{ }^{0}$ for initial $\mathrm{Ni}$ concentrations ranging from 17 to $426 \mu \mathrm{mol} / \mathrm{L}$.

\subsection{Concentration determinations and column chromatographic purification of $\mathrm{Ni}$}

All manipulations were performed in a class 1000 clean room and exclusively used acid-cleaned plasticware and teflonware. Solid samples were digested in $6 \mathrm{~mol} / \mathrm{L} \mathrm{HCl}$ at room temperature for 72 hours. The total concentrations of $\mathrm{Ni}$ and $\mathrm{Fe}$ in the solids were determined by quadrupole ICP-MS (X-series2, Thermo Scientific) at the Pôle Spectrométrie Océan (PSO, Brest, France). Nickel concentrations in the filtrates were first estimated by mass balance using the initial concentrations in solutions used at the start of each experiment and the $\mathrm{Ni}$ concentrations in the solids determined by quadrupole ICP-MS at the end of the experiment. Nickel concentrations were then recalculated by isotope dilution after isotope measurements. For the separation of $\mathrm{Ni}$ onto chromatographic columns, an aliquot of each filtrate was evaporated to dryness at $80^{\circ} \mathrm{C}$ prior to redissolution in $1 \mathrm{ml}$ of $6 \mathrm{~mol} / \mathrm{L} \mathrm{HCl}$. A full description of the purification method can be found in Gueguen et al. (2013). Briefly, our two-step separation procedure involved: (1) separation of Fe onto an anion exchange chromatographic resin (BioRad AG1-X8, 100-200 mesh); (2) separation of Ni from the remaining matrix using 
a Ni-specific resin (Ni-Spec by Eichrom). This Ni-resin contains dimethylglyoxime (DMG) functional groups, which complexes $\mathrm{Ni}$ in ammonium citrate solutions at $\mathrm{pH}$ 8-9. Nickel is then eluted with $3 \mathrm{~mol} / \mathrm{L} \mathrm{HNO}_{3}$ after breakdown of the Ni-DMG complex.

\subsection{Ni isotope mass spectrometry and double-spike correction scheme}

Nickel isotope compositions were measured by MC-ICP-MS (Neptune, Thermo Scientific) at the PSO (Brest, France) using a double spike for mass bias correction following the method described in Gueguen et al. (2013). The double spike is a mixture of ${ }^{61} \mathrm{Ni}$ and ${ }^{62} \mathrm{Ni}$ that was added to samples at spike/natural ratio of 1 prior to the chromatographic separation on $\mathrm{Ni}$-specific resin. Corrected ratios were calculated using an iterative scheme following the method described by Siebert et al. (2001). An ESI (Elemental Scientific Inc., USA) desolvating introduction system (ApexQ) was employed for all measurements. The nine Faraday cups of the instrument allowed simultaneous measurement of $\mathrm{Ni}$ isotopes ${ }^{58} \mathrm{Ni},{ }^{60} \mathrm{Ni}$, ${ }^{61} \mathrm{Ni},{ }^{62} \mathrm{Ni},{ }^{64} \mathrm{Ni}$, and potential isobaric interferences from $\mathrm{Zn}$ (measured on ${ }^{66} \mathrm{Zn}$ ) and $\mathrm{Fe}$ (measured on ${ }^{57} \mathrm{Fe}$ ). Argon oxide interferences (e.g., ${ }^{40} \mathrm{Ar}^{18} \mathrm{O}^{+}$on ${ }^{58} \mathrm{Ni}^{+}$and ${ }^{40} \mathrm{Ar}^{17} \mathrm{O}$ on ${ }^{57} \mathrm{Fe}$ ) were resolved using the medium resolution mode of the MC-ICP-MS.

Nickel isotope values were reported according to the conventional delta notation (equation 1) relative to the Ni international isotopic standard NIST SRM 986 :

$$
\delta^{60 / 58} \mathrm{Ni}(\%)=\left({ }^{60 / 58} \mathrm{Ni}_{\text {sample }} /{ }^{60 / 58} \mathrm{NiNIST} 986-1\right) \times 1000
$$

For each sample, 50 measurement cycles were performed, resulting in an internal standard error (2se) value typically between 0.02 and $0.04 \%$. The external precision was evaluated through the duplicated measurements of geostandards (USGS Nod-P-1, $\delta^{60 / 58} \mathrm{Ni}=0.33 \%$; and

USGS Nod-A-1, $\delta^{60 / 58} \mathrm{Ni}=1.04 \%$ ) and was found to be $\sim 0.06 \%$ ( $\left.2 \mathrm{sd}\right)$. 


\section{Results}

\subsection{Nickel sorption by Fe oxyhydroxides}

The loadings of Ni onto both 2-line ferrihydrite and goethite expressed in terms of the percent of $\mathrm{Ni}$ sorbed for $\mathrm{pH}$-dependent and varying initial [Ni] experiments are displayed in Table 1. The sorption of $\mathrm{Ni}$ onto 2-line ferrihydrite for $\mathrm{pH}$ ranging from 5.0 to 8.0 (i.e., $\mathrm{pH}$ dependent experiments, with initial Ni concentration of $170 \mu \mathrm{mol} / \mathrm{L}$ ) resulted in $\mathrm{Ni}$ uptake between $<1 \%$ and $45 \%$ translating into 0.02 to $0.62 \mu \mathrm{mol} \mathrm{Ni} / \mathrm{m}^{2}$ mineral (Figure 1a). At $\mathrm{pH}$ 7.7 (varying initial Ni concentrations experiments, 17 to $426 \mu \mathrm{mol} / \mathrm{L} \mathrm{Ni}$ ), final Ni loadings on 2-line ferrihydrite ranged from 0.11 to $1.71 \mu \mathrm{mol} \mathrm{Ni} / \mathrm{m}^{2}$ mineral (Figure 1), which correspond to a percentage of sorbed Ni between $25 \%$ and $78 \%$.

Nickel sorption to goethite at $\mathrm{pH} 5.0,6.0$, and 8.0 resulted in $\mathrm{Ni}$ uptake between $<1 \%$ and $4.3 \%$ of the initial $170 \mu \mathrm{mol} / \mathrm{L}$ aqueous Ni (Figure 1), corresponding to Ni loadings ranging from 0.04 and $0.28 \mu \mathrm{mol} \mathrm{Ni} / \mathrm{m}^{2}$. At $\mathrm{pH} 7.7$, Ni uptake from solutions with initial concentrations of 17,170 , and $426 \mu \mathrm{mol} / \mathrm{L} \mathrm{Ni}$ yielded final Ni loadings onto the mineral between 0.63 to $1.33 \mu \mathrm{mol} \mathrm{Ni} / \mathrm{m}^{2}$, corresponding to percentage of sorbed Ni between $8 \%$ and $19 \%$.

Zeta potential measurements at $\mathrm{pH} 7$ indicated that 2-line ferrihydrite exhibits a net negative surface charge with a value of $-3.44 \mathrm{mV}$ (Electronic Annex, Table A1). Zeta potential measurements at $\mathrm{pH} 7$ indicated that goethite exhibits a net positive surface charge with a value of $+3.46 \mathrm{mV}$. 2-line ferrihydrite has more Ni-sorbed at $\mathrm{pH} 7$ than goethite, which is consistent with the more negative surface charge of 2-line ferrihydrite relative to goethite.

\subsection{Surface complexation modeling}


Constant capacitance surface complexation modeling (CCM) for Ni adsorption to 2-

line ferrihydrite and goethite (Figure 2) was implemented using adsorption parameters provided by Dzombak and Morel (1990), Xu et al. (2006) and Davis and Kent (1990), in order to verify that sorption processes control $\mathrm{Ni}$ behavior in our experiments. Our experimental data for 2-line ferrihydrite were in good agreement with the surface complexation model calculated with parameters from Dzombak and Morel (1990) (Figure 2). The best fit of our data for Ni adsorption to goethite was obtained with a constant capacitance model (Figure 2) generated using adsorption constants from Xu et al. (2006) for bidentate adsorption in the Nigoethite system, our BET-measured surface area of $25.5 \mathrm{~m}^{2} / \mathrm{g}$, solid concentrations close to 1 $\mathrm{g} / \mathrm{L}$, and a goethite site density of 1 site per $\mathrm{nm}^{2}$. Adopting higher literature values for the latter (e.g., 2.3 sites per $\mathrm{nm}^{2}$ (Davis and Kent, 1990) or 6 sites per $\mathrm{nm}^{2}$ (Xu et al., 2006)) results in model adsorption values significantly higher than what was observed. Finally, it is important to point out that the CCM is a simple surface complexation model that integrates a smaller number of parameters in comparison to the diffuse-layer model and the triple-layer models (Hayes et al., 1991) and thus may not approximate natural conditions as closely.

\subsection{Nickel K-edge EXAFS Spectroscopy}

Nickel K-edge EXAFS spectra were collected for six Ni-sorbed 2-line ferrihydrite samples (Fh-pH-05, Fh-C-07, Fh-C-08, Fh-C-09, and Fh-C-10) and one Ni-sorbed goethite sample (Goe-C-06) as indicated in Table 1. The Ni K-edge EXAFS spectra collected for the 2-line ferrihydrite samples at pH 7.7 and 8.0 are similar in phase and amplitude despite different Ni-loadings and $\mathrm{pH}$ values (displayed in k-space with best fits; Figure 3). All Ni Kedge EXAFS spectra were fit with $\sim 6 \mathrm{Ni}-\mathrm{O}$ atom pairs in the first-shell at a distance of $2.05 \pm$ 
$0.01 \AA$ (Table 3). For the Ni-Fe second-shell atom pairs, two sub-shells were required to describe the data: 1.5 Ni-Fe (type 1) at 3.10 $\pm 0.02 \AA$ and $\sim 0.6 \mathrm{Ni}-\mathrm{Fe}$ (type 2) at 3.56-3.60

$\pm 0.06 \AA$ A. Errors in the second shell coordination numbers were estimated using the fractional parameter error as an indicator. As these error values were low we estimated $\mathrm{CN}$ error to be $\sim 25 \%$ of the value.

The magnitude and imaginary portion of the Fourier transformed Ni K-edge EXAFS spectra and fits are displayed in Figure 4. The only notable difference in the Ni K-edge EXAFS derived fit parameters obtained for 2-line ferrihydrite and goethite was a lower Ni-Fe coordination number in the type 1 second shell for Ni-sorbed goethite. Nickel sorbed to goethite had on average $1.0 \pm 0.4 \mathrm{Fe}$ in its second shell, while Ni-sorbed to 2-line ferrihydrite had an average of $2.2 \pm 0.56 \mathrm{Fe}$ atoms in its second shell (Table 3). This difference can be viewed by comparing peak amplitudes of the two minerals whereby 2-line ferrihydrite samples have greater peak amplitudes than goethite. The Ni K-edge EXAFS data are also consistent with the formation of inner-sphere complexes with no evidence for a separate $\mathrm{Ni}$ phase.

\subsection{The Ni isotope composition of sorbed Ni and supernatant solutions}

The Ni isotope composition of the initial Ni stock solution was determined at $\delta^{60 / 58} \mathrm{Ni}$ $=-0.33 \pm 0.05 \%$ o $(2 \mathrm{sd}, \mathrm{n}=4$, Table 1$)$. The $\mathrm{Ni}$ isotope compositions of mineral-associated $\mathrm{Ni}$ (i.e, sorbed onto 2-line ferrihydrite and goethite) and solution are reported in Table 1.

The difference in $\mathrm{Ni}$ isotopic composition between the mineral sorbed-Ni and $\mathrm{Ni}$ remaining in solution, which we define as the fractionation factor, is expressed as $\Delta^{60 / 58} \mathrm{Ni}_{\text {min- }}$ aq (equation 2) according to: 
375

Figure 5 presents $\delta^{60 / 58} \mathrm{Ni}$ values of the mineral and the associated filtrate versus corresponding percent $\mathrm{Ni}$ sorbed in $\mathrm{pH}$-dependent, variable initial $\mathrm{Ni}$ concentration and timedependent experiments. The results show a systematic enrichment in light $\mathrm{Ni}$ isotope compared to the starting solution during Ni sorption to the mineral surface, which is accompanied by enrichment of the residual aqueous $\mathrm{Ni}$ in heavy isotopes. Isotopic mass balance (equation 3), was verified for each sample and was consistent within uncertainty with the $\mathrm{Ni}$ isotope composition of the original stock solution (Table 1).

$\delta^{60 / 58} \mathrm{Ni}$ bulk $=\left(\% \mathrm{Ni}_{\text {sorbed }} / 100 \times \delta^{60 / 58} \mathrm{Ni}_{\text {mineral }}\right)+\left(\left(1-\% \mathrm{Ni}_{\text {sorbed }} / 100\right) \times \delta^{60 / 58} \mathrm{Ni}_{\text {aqueous }}\right)$

The magnitude of the $\mathrm{Ni}$ isotope fractionation factor $\Delta^{60 / 58} \mathrm{Nimin-aq}$ (equation 2) between the solid phase and aqueous phase is larger for goethite $(-0.77 \pm 0.23 \%$ ) than for 2-line ferrihydrite $(-0.32 \pm 0.20 \%$ ), with no significant correlation with the percentage of adsorption (Figures 5 and 7). We observe consistent and similar $\Delta^{60 / 58} \mathrm{Ni}_{\text {min-aq }}$ values for $\mathrm{pH}$-dependent and variable Ni concentration experiments for 2-line ferrihydrite on the one hand, and for goethite on the other hand.

The $\mathrm{pH}$-dependent adsorption experiments on 2-line ferrihydrite yielded surface loadings from 0.02 to $0.62 \mu \mathrm{mol} \mathrm{Ni} / \mathrm{m}^{2}$ mineral with $\Delta^{60 / 58} \mathrm{Ni}$ min-aq values ranging from -0.37 to $-0.03 \%$ (Figure 6). At low loadings of $\mathrm{Ni}$ onto 2-line ferrihydrite, i.e., $0.02-0.04 \mu \mathrm{mol}$ $\mathrm{Ni} / \mathrm{m}^{2}$ mineral which correspond to 1 and $3 \%$ percent of to the total added $\mathrm{Ni}$ sorbed in the $\mathrm{pH}$ 5.0 and 6.0 experiments, $\mathrm{Ni}$ isotopes were not fractionated $\left(\Delta^{60 / 58} \mathrm{Ni}_{\text {min-aq }}=-0.03 \%\right)$ or weakly fractionated $\left(\Delta^{60 / 58} \mathrm{Ni}_{\text {min-aq }}=-0.12 \%\right)$ respectively. Although Figure 6 seems to indicate that decreasing $\Delta^{60 / 58} \mathrm{Ni}_{\text {min-aq }}$ values are correlated with increasing $\mathrm{pH}$ for 2-line ferrihydrite, we 
399

400

401

402

403

404

405

406

407

408

409

410

411

412

413

414

415

416

417

418

419

420

421

422

423

think these data are an artifact since low $\mathrm{pH}$ values (5.0 and 6.0) also correspond to very low Ni loadings (see discussion). For this reason, we decided to not include these data when discussing average $\mathrm{Ni}$ isotope fractionation factors. In contrast, at $\mathrm{pH} 7.7$, the percent $\mathrm{Ni}$ sorbed was generally higher and $\mathrm{Ni}$ loadings of $0.32-1.71 \mu \mathrm{mol} \mathrm{Ni} / \mathrm{m}^{2}$ mineral were achieved, which represent between 23 and 78\% Ni-sorbed on 2-line ferrihydrite. This gave a range of $\Delta^{60 / 58} \mathrm{Nimin-aq}$ values between -0.40 and $-0.24 \%$ (Figures 6 and 7).

Nickel sorption by goethite for the $\mathrm{pH}-$ dependent experiment was minimal, ranging from 0.6 to $4 \%$ of the initial $\mathrm{Ni}$ (corresponding to loadings of $0.04-0.28 \mu \mathrm{mol} \mathrm{Ni} / \mathrm{m}^{2}$ mineral), and $\mathrm{Ni}$ isotope fractionation was characterized by $\Delta^{60 / 58} \mathrm{Ni}$ min-aq values between -0.96 and $-0.70 \%$ (Figure 6). At pH 7.7 and for different initial Ni concentrations, final loadings of $\mathrm{Ni}$ of 0.63 to $1.33 \mu \mathrm{mol} \mathrm{Ni} / \mathrm{m}^{2}$ mineral yielded $\Delta^{60 / 58} \mathrm{Ni}$ min-aq values between -1.03 and -0.78 \%o (Figure 6). Goethite with the lowest loading of $\mathrm{Ni}$ (also corresponding to the lowest $\mathrm{pH}$ ) displayed the smallest $\mathrm{Ni}$ isotope fractionation factor relative to other samples, with $\Delta^{60 / 58} \mathrm{Ni}_{\text {min-aq }}=-0.70 \%$ and $-0.88 \%$ for $\mathrm{pH} 5.0$ and 6.0 , respectively. The largest $\Delta^{60 / 58} \mathrm{Ni}_{\text {min- }}$ aq value of $-1.03 \%$ was measured at $\mathrm{pH} 7.7$ for goethite with the highest Ni loading.

Time-dependent experiments were performed in order to identify potential kinetic effects (i.e., non-equilibrium $\mathrm{Ni}$ fractionation) in our experiments. Experiments were conducted for four different durations, i.e., 18 or $19,20,22$, and 23 hours and for two different initial Ni concentrations of $170 \mu \mathrm{mol} / \mathrm{L}$ and $426 \mu \mathrm{mol} / \mathrm{L}$ (Table 2). The Ni isotope fractionation factor $\Delta^{60 / 58} \mathrm{Ni}_{\text {min-aq }}$ is between -0.77 and $-0.72 \%$ (average $\Delta^{60 / 58} \mathrm{Ni}_{\text {min-aq }}=-0.75$ $\pm 0.05 \% ; 2 \mathrm{sd}, \mathrm{n}=4$ ) and $\Delta^{60 / 58} \mathrm{Ni}_{\text {min-aq }}$ values are between -0.73 to $-0.62 \%$ (average $\left.\Delta^{60 / 58} \mathrm{Ni}_{\text {min-aq }}=-0.67 \pm 0.09 \% ; 2 \mathrm{sd}, \mathrm{n}=4\right)$ for the two experiments respectively.

\section{Discussion}


Previous work on non-traditional isotope systems, such as Mo (Barling and Anbar,

2004; Goldberg et al., 2009; Kashiwabara et al., 2009; Wasylenki et al., 2011), Zn (Pokrovsky et al., 2005; Juillot et al., 2008), Cu (Balistrieri et al., 2008; Pokrovsky et al., 2008), Tl (Rehkämper et al., 2002), Cd (Wasylenki et al., 2014), Hg (Jiskra et al., 2012), Fe (Icopini et al., 2004; Mikutta et al., 2009; Beard et al., 2010; Wu et al., 2011; Wu et al., 2012; Frierdich et al., 2014), Ge (Li and Liu, 2010; Pokrovsky et al., 2014), and Se (Mitchell et al., 2013) have shown that adsorption reactions are often accompanied by significant isotope fractionation processes that may vary according to sorbent composition and sorbate structure. By contrast, sorption of $\mathrm{Cr}(\mathrm{VI})$ to Fe-oxyhydroxides is not accompanied by significant isotope fractionation (Ellis et al., 2004). Hence, the combination of spectroscopic and isotopic measurements is essential for understanding isotopic fractionation processes. Here, we discuss the result of both approaches to address the mechanisms and significance of $\mathrm{Ni}$ isotope fractionation during Ni sorption to Fe-oxyhydroxides.

\subsection{Surface coordination of Ni at the mineral surface}

Coordination chemistry (i.e., coordination number, bond length) correlates with the extent of isotope fractionation because shorter bond lengths (i.e., stiffer bonds) or lower coordination numbers favor enrichment of heavier isotopes (e.g., Schauble, 2004; Pokrovsky et al., 2005). The first coordination shell of a metal is comprised of oxygen atoms. Variations of the coordination number of the metal (e.g., between the aqueous phase and the solid phase) during adsorption of a transition metal to the surface of any given Fe-oxyhydroxide mineral is a common cause for isotope fractionation. For instance, heavy isotope enrichment during $\mathrm{Zn}$ sorption on ferrihydrite was accounted for by a decrease in the coordination number of the aqueous species relative to the adsorbed species. According to EXAFS data, the adsorption of 
Zn onto ferrihydrite produces a significant shift in $\mathrm{Zn}$ coordination number, from 6 in the solution to 4 in the solid, while $\mathrm{Zn}$ sorbed on goethite occurs in octahedral coordination, i.e., similar to aqueous $\mathrm{Zn}$. The larger isotope fractionation factor measured for ferrihydrite relative to goethite can thus be explained by a different coordination environment of the sorbed $\mathrm{Zn}$ (i.e., 4 for ferrihydrite and 6 for goethite) and differences in $\mathrm{Zn}-\mathrm{O}$ bond stiffness (i.e., $1.96 \AA$ for ferrihydrite and $2.11 \AA$ for goethite; Juillot et al., 2008). For Ni, isotopic fractionation cannot be related to changes in the coordination number between aqueous $\mathrm{Ni}$ and sorbed $\mathrm{Ni}$ because $\mathrm{Ni}$ exclusively occurs in coordination 6 in the natural environment. The length of $\mathrm{Ni}-\mathrm{O}$ bonds in water is $2.1 \AA$ compared to the $2.05 \AA$ observed when $\mathrm{Ni}$ is sorbed to the mineral surface (Soper et al., 1977), therefore, heavier Ni isotopes enrichment should be expected during sorption to the mineral surface. The systematic enrichment in lighter Ni isotopes on the mineral phase found in this study and in Wasylenki et al. (2015) precludes this option.

Wasylenki et al. (2015) suggest that distortion of the coordination environment after $\mathrm{Ni}$ sorption to ferrihydrite could explain light $\mathrm{Ni}$ isotopes enrichment of the mineral surface. Given our Ni K-edge EXAFS data quality it was not possible to support or refute this hypothesis because we could not achieve fitting multiple $\mathrm{Ni}-\mathrm{O}$ paths to the Ni-O shell (first coordination shell). However, the number of bonds between $\mathrm{Ni}$ and surface oxygens, which is reflected in the second shell parameters (i.e., surface complex geometry), may cause slight distortion or distribution of the electron density in the first coordination shell, even if they cannot be captured by the Ni K-edge EXAFS data. Thus, we argue that the number of bonds between $\mathrm{Ni}$ and surface oxygens could distort the first coordination shell. Consistent with previous studies (Manceau et al., 2000; Carvalho-E-Silva et al., 2003; Arai, 2008; Dublet et al., 2012) adsorbed Ni displayed octahedral coordination (Electronic Annex, Table A2). For an inner-sphere surface complex of $\mathrm{Ni}$ on $\mathrm{Fe}$ oxyhydroxides, the 
second major coordination shell is composed of Fe atoms. The interatomic distances between $\mathrm{Ni}$ and Fe, as measured by Ni K-edge EXAFS spectroscopy, define the local coordination environment of the Ni surface species and Ni sorbed on ferrihydrite and goethite have been studied in detail (Waychunas et al., 2002; Arai, 2008; Juillot et al., 2008; Dublet et al., 2012; Cismasu et al., 2013). It was demonstrated that Ni sorbed on ferrihydrite occurs in octahedral coordination between $\mathrm{Ni}-\mathrm{O}_{6}$ and $\mathrm{Fe}-\mathrm{O}_{6}$ polyhedra with interatomic distances in the range of 3.05-3.08 $\AA$ for edge-sharing type 1 surface complexes, 3.19-3.12 $\AA$ for edge-sharing type 2 , and 4.03-4.07 $\AA$ for corner-sharing (Arai, 2008). Type 1 edge sharing is between $\mathrm{Ni}$ and $\mathrm{Fe}$ octahedra in the chains and type 2 surface complexes is between $\mathrm{Ni}$ and Fe octahedra in the rows (Arai, 2008). The interatomic distances modeled here for goethite samples reflect the three $\mathrm{Fe}-\mathrm{Fe}$ second-shell interatomic distances for edge-sharing coordination between $\mathrm{Ni}$ and a chain of $\mathrm{Fe}-\mathrm{O}_{6}$ octahedra (i.e., type 1), edge-sharing between chains of $\mathrm{Fe}-\mathrm{O}_{6}$ octahedra (i.e., type 2), and corner-sharing Fe-O6 octahedra between double chains (Manceau and Drits, 1993).

$$
\text { Incorporation of } \mathrm{Ni} \text { into } \mathrm{Fe} \text {-oxyhydroxides lattices is possible, but our } \mathrm{Ni} \mathrm{K} \text {-edge }
$$
EXAFS data shows the absence of Ni incorporation in the minerals. Cornell et al. (1992) reported $\mathrm{Ni}$ incorporation into synthetic goethite at $\sim 5 \%$ of the total molar fraction and several studies showed that incorporation of $\mathrm{Ni}$ in goethite occurs via diffusion into the mineral lattice where Ni can occupy vacant Fe positions in synthetic goethite (Barrow et al., 2012; Brümmer et al., 2013). Fischer et al. (2007) showed that Ni reaction with the goethite surface is continuous with time and that $\mathrm{Ni}$ is incorporated via diffusion in the lattice structure of the mineral. Wasylenki et al. (2015) reported nearly identical isotopic signatures for surface sorbed $\mathrm{Ni}$ and incorporated $\mathrm{Ni}$, suggesting that the influence of incorporated $\mathrm{Ni}$ is negligible in the isotopic budget and that potential $\mathrm{Ni}$ isotope fractionation during diffusion can be precluded. 
$500 \mathrm{Ni}-\mathrm{Fe}$ distances in the second shell, is consistent with a short Ni-Fe distance produced by

501 edge-sharing polyhedra $(3.10 \pm 0.02 \AA)$ in addition to a longer $\mathrm{Ni}$-Fe distance produced by a combination of edge-sharing and corner-sharing polyhedra not resolved by our Ni K-edge EXAFS data $(3.57 \pm 0.06 \AA)$. The data quality for the Ni-sorbed goethite prevented a robust second-shell fit to the Ni K-edge EXAFS. However, the fit results were consistent with a NiFe atom pair at $3.07 \pm 0.03 \AA$ and revealed a difference relative between goethite and 2-line ferrihydrite in the Ni-Fe coordination number. The Ni K-edge EXAFS measurements on goethite and 2-line ferrihydrite from this study also indicate that the Ni coordination environment was similar among all samples. Therefore, the difference in Ni isotope fractionation between the two minerals may be due to minor differences in surface site density and distribution. Since no detectable difference in surface speciation was observed as a function of Ni loading to the 2-line ferrihydrite surface at $\mathrm{pH} 7.7$ or as a function of $\mathrm{pH}$ (7.7 versus 8.0), alternative variable parameters such as protonation state of the mineral, surface complex geometry (e.g., number of bonds between $\mathrm{Ni}$ and mineral surface), surface coverage or bond lengths between the two minerals might have influenced $\mathrm{Ni}$ isotope fractionation.

\subsection{Nickel isotope fractionation factors during Ni adsorption to Fe-oxyhydroxides}

In the case of equilibrium isotopic fractionation, the fractionation factor between mineral and solution, the $\alpha_{\text {min-aq }}$ value (related to $\Delta^{60 / 58} \mathrm{Ni}_{\text {min-aq }}$ values as $\approx 10^{3} . \ln \alpha_{\text {min-aq }}$ ), ultimately depends on the difference in bond stiffness between two species involved in the reaction. In a closed system, the $\mathrm{Ni}$ isotope composition of the solution and mineral-bound $\mathrm{Ni}$ are related to the proportion of $\mathrm{Ni}$ sorption to the mineral (Figure 5). If equilibrium isotope fractionation is maintained during the experiment, the fractionation factor, $\Delta^{60 / 58} \mathrm{Ni}_{\text {min-aq }}$, 
should remain constant regardless of the percentage of Ni adsorption and duration of the experiments. We recognize that equilibrium isotope fractionation is best demonstrated using the 3-isotopes method (Wu et al., 2011), which allows the determination of the rate of isotopic exchange and extrapolate the isotope fractionation factors during incomplete isotope exchange. Here, we mainly relied on the constant $\mathrm{Ni}$ isotope fractionation factor between solution and mineral during the reaction progress in order to derive equilibrium $\Delta^{60 / 58} \mathrm{Nimin}$-aq values. Results obtained for 2-line ferrihydrite and goethite (i.e., $\mathrm{pH}$ dependent, concentration dependent, and time dependent) are for the most part consistent with isotopic equilibrium in a closed system (i.e., constant $\Delta^{60 / 58} \mathrm{Ni}_{\text {min-aq }}$ values), although significant departure from this relationship is observed at low percentage of $\mathrm{Ni}$ sorption (Figure 7) and in one goethite sample (i.e., the variable initial Ni concentrations experiments with 19.3\% Ni-sorbed (Figure 5)).

In order to derive meaningful $\mathrm{Ni}$ isotope fractionation factors from the experimental data, the $\%$ of $\mathrm{Ni}$ adsorption should be generally comprised between $5 \%$ to $95 \%$, i.e., too low or too high values may pose problem in the determination of $\delta^{60 / 58} \mathrm{Ni}$ of the mineral and solution, respectively. Using this more restricted dataset, we determine an average $\Delta^{60 / 58} \mathrm{Ni}_{\text {min- }}$ aq $=-0.32 \pm 0.20 \%$ for the 2-line ferrihydrite and $\Delta^{60 / 58} \mathrm{Nimin}$-aq $=-0.77 \pm 0.23 \%$ for goethite. For time-dependent experiments, we determine a range of $\Delta^{60 / 58} \mathrm{Ni}_{\text {min-aq }}$ values for the 2-line ferrihydrite between $-0.32 \pm 0.04$ and $-0.38 \pm 0.06 \%$, and for goethite between -0.65 \pm 0.07 and $-0.77 \pm 0.07 \%$. Therefore, $\Delta^{60 / 58} \mathrm{Ni}_{\text {min-aq }}$ values do not vary within uncertainties over the course of the experiments. This is in agreement with previous results of Wasylenki et al. (2015) showing no variations in $\Delta^{60 / 58} \mathrm{Ni}_{\text {min-aq }}$ values for 2-line ferrihydrite for experiment duration between a few hours to 30 days. There is also no appreciable difference in the magnitude of $\mathrm{Ni}$ isotope fractionation factor depending on the initial $\mathrm{Ni}$ concentration and sorption \%, i.e., $\Delta^{60 / 58} \mathrm{Ni}_{\text {min-aq }}=-0.35 \pm 0.01 \% 0(2 \mathrm{sd}, \mathrm{n}=4)$ for an initial $\mathrm{Ni}$ concentration of 

$170 \mu \mathrm{mol} / \mathrm{L}$ and $\Delta^{60 / 58} \mathrm{Ni}_{\text {min-aq }}=-0.36 \pm 0.05 \%$ o $(2 \mathrm{sd}, \mathrm{n}=4)$ for an initial Ni concentration of $426 \mu \mathrm{mol} / \mathrm{L}$ (Table 2). Average $\Delta^{60 / 58} \mathrm{Nimin}$-aq values for 2-line ferrihydrite and goethite timedependent experiments are also similar to the average value calculated for the $\mathrm{pH}$-dependent and varying initial $\mathrm{Ni}$ concentrations experiments suggesting that our experiments are at isotopic equilibrium. The duration of experiments is the same for low Ni-sorbed samples than for high Ni-sorbed samples. Therefore, if there were any kinetic effects we would expect them to be similar whatever the amount of sorbed $\mathrm{Ni}$ or that larger isotope fractionation would occur for low $\mathrm{Ni}$-sorbed samples compared to high $\mathrm{Ni}$-sorbed samples which is not the case in our experiments. Although these experiments did not allow the determination of isotopic exchange rates between the solution and the mineral, which would have required shorter experiment duration, we suggest that isotopic equilibrium was likely achieved in our experiments. This assumption is also consistent with previous goethite adsorption experiments for $\mathrm{Cu}$ and $\mathrm{Zn}$ isotopes systematics (Pokrovsky et al., 2005; Pokrovsky et al., 2008) for which isotope fractionation factors were similar for short duration experiments ( 20 hours) than for long duration experiments ( 100 days).

The smaller Ni isotope fractionation factors for goethite and 2-line ferrihydrite at low $\%$ (Figure 7) can be explained in several ways: (1) non-equilibrium fractionation (i.e., kinetic fractionation processes) due to partially irreversible reaction between sorbed $\mathrm{Ni}$ on the mineral and $\mathrm{Ni}$ in solution; (2) a change in coordination chemistry in the mineral with $\mathrm{pH}$ and/or Ni loading; and (3) retention of aqueous $\mathrm{Ni}$ on the mineral during filtration, leading to incomplete separation of $\mathrm{Ni}$ in mineral and $\mathrm{Ni}$ in solution. As explained above, timedependent experiments suggest that isotopic equilibrium is achieved which, thus, discounts hypothesis (1). Hypothesis (2) can also be ruled out since no change in coordination chemistry as a function of $\mathrm{pH}$ was observed in the Ni K-edge EXAFS measurements. We propose that the low $\Delta^{60 / 58} \mathrm{Ni}_{\text {min-aq }}$ values measured in samples prepared at low $\mathrm{pH}$ may be due 
to the presence of a small fraction of the supernatant solution that remained trapped in the mineral even after filtering, which would mute Ni isotope fractionation during adsorption. Using the final Ni concentration measured in supernatant solutions and the estimated volume of water present in the mineral, we calculated that the supernatant solution should contribute between 0.0002 and $0.0070 \mu \mathrm{mol} \mathrm{Ni} / \mathrm{m}^{2}$ for 2-line ferrihydrite. Hence, for low Ni-loading in the 2-line ferrihydrite experiments, $\mathrm{Ni}$ in solution may account for between $13 \%$ and $44 \%$ of the total $\mathrm{Ni}$ in the sorbed fraction. This mixing effect is the most plausible explanation (hypothesis 3 ) for the variation in $\Delta^{60 / 58} \mathrm{Nimin-aq}$ values (i.e., decrease) at low Ni-loading.

\subsection{Differences in Ni isotope fractionation between goethite and 2-line ferrihydrite}

Our experiments showed that Ni sorbed to goethite is twice more fractionated towards lighter $\Delta^{60 / 58} \mathrm{Ni}_{\text {min-aq }}$ values $(\sim-0.77 \%$ o) than $\mathrm{Ni}$ sorbed to 2-line ferrihydrite $(\sim-0.35 \%$ ).

Nickel species in solution that are likely to be adsorbed onto minerals are the $\mathrm{Ni}^{2+}$ (hexaquo) species (Peacock and Sherman, 2007a). The surface complexation model reported in Figure 2 predicts that under the experimental conditions used in our study Ni should sorb to goethite to a greater extent than we observed in our experiments. At $\mathrm{pH}$ values less than $~ 8.0$, the expected point of zero net charge for goethite is such that it should be positively charged. In contrast, the zeta potential measurements for 2-line ferrihydrite indicate a net negatively charged surface. The net negative surface charge of 2-line ferrihydrite tends to attract dissolved cations to its surface while the net positive surface charge of goethite tends to repel dissolved cations and ferrihydrite has a higher surface area than goethite. This is in agreement with the strong uptake of $\mathrm{Ni}$ from solution by 2-line ferrihydrite observed in our experiments and predicted by our surface complexation model (Figure 2). 
599 Fe-oxyhydroxides. One involves isotopic exchange among aqueous species in solution 600 followed by preferential adsorption of one of these species onto the mineral phase. This mechanism may lead to contrasting isotope composition between the fluid and mineral, as previously observed for the Mo isotope system (Siebert et al., 2003; Barling and Anbar, 2004). An alternative mechanism of fractionation may take place directly during metal adsorption and involves the preferential adsorption of one isotope from the aqueous phase onto the solid phase because of, for instance, differences in coordination chemistry or kinetic effects. These two mechanisms are not mutually exclusive and combination of the two is likely to occur in natural systems. Pokrovsky et al. (2014) identified five mechanisms that could be responsible for equilibrium isotope fractionation during sorption reactions: (1) protonation of metal species in solution or on the mineral surface; (2) mineral surface coverage and distribution of weak sites versus strong sites; (3) bond distances between the metal and oxygen atoms and the presence of other atoms in the mineral structure; (4) change in coordination between the fluid and the solid phase; and (5) binding mode of the metal. Below we evaluate each of these mechanisms in light of the results from our study.

Mechanism (1) : Protonation of aqueous or sorbed Ni. As a divalent cation, Ni has a relatively low ionic potential, e.g., in contrast to $\mathrm{Fe}^{3+}$ and $\mathrm{Al}^{3+}$. Hence, $\mathrm{Ni}\left(\mathrm{H}_{2} \mathrm{O}\right) 6^{2+}$ does not readily undergo hydrolysis and $\mathrm{Ni}$ tends to form relatively weak aqueous complexes with ligands when compared to trivalent cations. In addition, because we expect the presence of a single aqueous $\mathrm{Ni}$ species, $\mathrm{Ni}\left(\mathrm{H}_{2} \mathrm{O}\right)_{6}{ }^{2+}$, in our experiments there should be no isotopic fractionation occurring in solution.

Mechanism (2) : Mineral surface coverage and distribution of weak and strong sites. Villalobos et al. (2003) demonstrated that goethite synthesized with variable $\mathrm{NaOH}$ addition rates yield variable site densities that are in turn reflected in adsorption behavior. The goethite 
minerals synthesized in our study appear to fall on the low end of surface site concentrations reported in literature for goethite. Our Ni K-edge EXAFS data and fits revealed no detectable differences between low and high Ni loadings onto 2-line ferrihydrite. Therefore, we have no evidence to support a fractionation mechanism based on discrimination between weak and strong sorption sites. The Ni loading data when normalized to mineral surface area show no distinct differences between 2-line ferrihydrite and goethite in terms of range or magnitude of Ni surface coverage (Figure 1 and Table 1). This suggests that mineral surface loading does not explain the $\mathrm{Ni}$ isotope fractionation observed in our experiments.

Mechanism (3): Bond distances between the metal and oxygen atoms and the presence of other atoms in the mineral structure. The minerals studied here were synthesized in the laboratory and are free of impurities. In addition, as discussed above, the Ni-O firstshell interatomic distances are indistinguishable among our 2-line ferrihydrite and goethite sorbents.

Mechanism (4): Change in coordination between the fluid and the solid phase. Based on thermodynamic modeling, we expect the aqueous $\mathrm{Ni}$ speciation is $>80 \% \mathrm{Ni}^{2+}$ (hexaquo), $\mathrm{Ni}\left(\mathrm{H}_{2} \mathrm{O}\right)_{6}{ }^{2+}$, and in octahedral coordination with O. Based on our Ni K-edge EXAFS data, the $\mathrm{Ni}$ sorbed to 2-line ferrihydrite and goethite is also in octahedral coordination with $\mathrm{O}$.

Mechanism (5): Metal bonding environment. The Ni K-edge EXAFS data and fit results indicate that the local coordination environment for $\mathrm{Ni}$ at the mineral surface is similar for all Ni loadings and $\mathrm{pH}$ values for 2-line ferrihydrite. To determine whether we can extend this finding to goethite, we compared two samples for which Ni K-edge EXAFS data were collected : (1) Goe-C-06 $\left(1.33 \mu \mathrm{mol} \mathrm{Ni} / \mathrm{m}^{2}\right)$ and Fh-C-10 $\left(1.71 \mu \mathrm{mol} \mathrm{Ni} / \mathrm{m}^{2}\right)$. These two samples have similar Ni loadings when the amount of adsorbed Ni is normalized by specific surface area (Table 1) and the Ni K-edge EXAFS-derived fit parameters for the Ni-O shell are identical within errors. In other words, the Ni species have the same coordination number and 
the same bond lengths for $\mathrm{Ni}-\mathrm{O}$ (recall some of the coordinating oxygens are contributed by the mineral and waters of hydration). The only difference in Ni speciation between the two samples is a lower Ni-Fe coordination number in the second shell for Ni-sorbed goethite. On average, the Ni sorbed to goethite has only 1.0 Fe (range 0.6-1.5) in its second shell, while Nisorbed to 2-line ferrihydrite has $2.2 \mathrm{Fe}$ (range 1.8-2.7) (Table 3). This difference in surface complex geometry, which may originate from the structure of goethite as discussed below, suggest that the number of bonds formed between $\mathrm{Ni}$ and surface oxygen atoms, as indicated by the number of Ni-Fe near neighbors, may influence the distribution of electron density in the first coordination shell of $\mathrm{Ni}$ and thus influence its isotopic fractionation.

Of these possible mechanisms, only mechanism (5) 'binding mode of the metal' provides a good explanation for our data. Specifically, we observe a subtle difference between the $\mathrm{Ni}$-Fe second-shell coordination environment when comparing two Ni-sorbed mineral samples having similar Ni loading when expressed in terms of surface area rather than total mass. Nickel sorbed to goethite has fewer Fe atoms in the second-shell than Ni sorbed to 2line ferrihydrite. The goethite structure is known to generate three different surface functional groups based on the number of Fe atoms bonded to a surface oxygen (Essington, 2003) : type $(1) \equiv \mathrm{Fe}_{3}-\mathrm{O}^{1 / 2-}$, type $(2) \equiv \mathrm{Fe}_{2}-\mathrm{O}^{1-}$, and type $(3) \equiv \mathrm{Fe}^{-} \mathrm{O}^{3 / 2-}$. In our experiments, sorption of $\mathrm{Ni}\left(\mathrm{H}_{2} \mathrm{O}\right)_{6}{ }^{2+}$ by site type (3) is most consistent with the results. In addition, fewer Fe atoms in the second coordination shell is consistent with weaker surface complexes and the observed enrichment of light $\mathrm{Ni}$ isotopes in the $\mathrm{Ni}$-sorbed to goethite sample leading to larger isotopic fractionation (i.e., larger fractionation factor $\Delta \delta^{60 / 58} \mathrm{Ni}_{\text {min-aq }}$ ) than for 2-line ferrihydrite.

\subsection{Implications for Ni isotope biogeochemical cycling in modern and ancient surface}

\section{environments}


In modern Earth surface environments, Fe-oxyhydroxides are likely an important carrier of Ni in riverine suspended sediments (Turekian, 1977; Snodgrass, 1980; Callender, 2014) and in soils (Dublet et al., 2012; Ratié et al., 2015). Snodgrass (1980) showed that Ni occurs in solution ( $0.5 \%$ only), as adsorbed species $(3.1 \%)$, as precipitated inorganic phases or particle coatings $(47 \%)$, as organic matter-bound complexes (14.9\%) and as crystalline material (34.4\%). Martin and Meybeck (1979) showed that Ni occurs mainly in the truly dissolved phase. However, a proportion of the total dissolved pool consists of Ni sorbed to Fe and Mn-oxides colloids and particles (Mouvet and Bourg, 1983; Gaillardet et al., 2014) while a significant proportion of $\mathrm{Ni}$ is associated with colloidal organic matter and organic compounds (Vasyukova et al., 2010). Considering that the proportion of each of these $\mathrm{Ni}$ pools in rivers may vary depending on environmental and geological settings, Ni speciation may exert a strong influence on the $\mathrm{Ni}$ isotope composition of rivers. Bedrock lithology, rock alteration processes and soil formation may be also important. For example, the Ni isotope composition of Ni-rich laterites forming through weathering of ultramafic complexes indicates an enrichment in light $\mathrm{Ni}$ isotopes by $-0.47 \%$ compared to the bedrock composition (Ratié et al., 2015). Nickel isotope fractionation during adsorption to Fe-oxyhydroxides might explain the observed light isotopes enrichment in weathering environment, and by isotopic mass balance, the overall enrichment in heavy isotopes in rivers (Cameron and Vance, 2014). This would indicate a significant role for $\mathrm{Fe}$ in $\mathrm{Ni}$ isotopic cycling on continental surfaces and more specifically in the delivery of $\mathrm{Ni}$ to the oceans both in terms of elemental flux and isotopic composition.

In natural environments, the reaction rate for the transformation of ferrihydrite to goethite can be relatively rapid (<500 days) and does not depend on pH (Schwertmann et al., 
2004), but ferrihydrite can be metastable in some environments (Navrotsky et al., 2008; Toner et al., 2012). The presence of large amounts of Ni incorporated in Fe-oxyhydroxides has been shown to slow the transformation of poorly crystalline Fe-oxyhydroxides to more crystalline phases (Cornell et al., 1992; Cornell and Schwertmann, 2003). During dissolution of Fe(III)oxyhydroxides, $\mathrm{Ni}$ is released more slowly than Fe, which leads to enrichment in $\mathrm{Ni}$ in the residual solid phase (Cornell et al., 1992). The presence of organic ligands in seawater may also affect the crystallization of ferrihydrite and its transformation to goethite (Cornell and Schwertmann, 1979). Therefore, in the case of differential Ni isotope fractionation between the two mineral phases as observed in this study, the overall $\mathrm{Ni}$ isotope composition of Feoxyhydroxides may be controlled by the nature of the initial mineral phase precipitated.

Based on our results, we propose that $\mathrm{Ni}$ adsorption on Fe-oxyhydroxides is likely to be a major mechanism for explaining the enrichment in heavy $\mathrm{Ni}$ isotopes in river water compared to the Bulk Silicate Earth by 0.6-0.7 \%o (Cameron and Vance, 2014). However, one should also consider the possibility that the present-day main river discharges (e.g., Amazon river) may contain some anthropogenic $\mathrm{Ni}$ as a by-product of fossil fuel burning, which may alter both the natural concentration of $\mathrm{Ni}$ in rivers and its isotopic composition. For instance, Gueguen et al. (2013) report a $\delta^{60 / 58} \mathrm{Ni}$ value of $0.5 \%$ in coal, which is heavier than the Bulk Silicate Earth isotopic composition. Such anthropogenic input could also explain the apparent $\mathrm{Ni}$ isotopic imbalance in the ocean (Cameron and Vance, 2014), thereby implying that Ni delivery to the ocean occurs under non steady-state conditions.

\subsubsection{Application to Precambrian seawater chemistry and ancient Ni biogeochemical cycling}

The marine biogeochemical cycle of $\mathrm{Ni}$ experienced major perturbations during the Precambrian (Konhauser et al., 2009; Konhauser et al., 2015), including an apparent sharp 
decrease in the Ni delivery to the ocean at the onset of the Great Oxidation Event, at ca. 2.5

Ga. Under the overall anoxic conditions and high Ni bioavailability of the Archean oceans, microorganisms such as methanogens may have been important primary producers. Given that methanogens fractionate light $\mathrm{Ni}$ isotopes by up to -1.5 \%o (Cameron et al., 2009), such a shift in Ni utilization in the oceans should have left characteristic imprints in the Ni isotopic composition of Precambrian seawater. Because Fe-oxyhydroxides were probably an important host phase for Ni in ancient marine environments (Konhauser et al., 2009), an understanding of $\mathrm{Ni}$ isotope fractionation during sorption to ferrihydrite or goethite is critical for inferring the Ni isotopic composition of Precambrian seawater from the Precambrian sediment record (Wasylenki et al., 2015). Tracing the evolution of Ni isotopic composition in Precambrian seawater by investigating BIFs could provide meaningful insights into the coevolution of the chemical composition of seawater with biological evolution and diversification (Bekker et al., 2010). However, Fe-oxides such as hematite and magnetite are the predominant carrier of $\mathrm{Ni}$ in these deposits, although accessory minerals such as silicates (e.g., stilpnomelane) and carbonates may be also important. Because the nature and origin of the Fe-oxyhydroxide precursor in BIF remain poorly known, interpretations based on the $\mathrm{Ni}$ isotope composition in BIF should be made with significant caution given the range of possible fractionation factors for different mineral types (e.g., ferrihydrite vs. goethite) and adsorption mechanisms.

Our results show that $\mathrm{Ni}$ isotope fractionation during abiotic reactions involving adsorption on Fe-oxides are of the same order of magnitude as for biotic reactions (i.e., Cameron et al., 2009) and vary between different mineral surfaces i.e., from -0.35 \%o (2-line ferrihydrite) to - $0.77 \%$ (goethite). Hence, the use of Ni isotopes as biosignatures should be approached with caution, as $\mathrm{Ni}$ isotope fractionation produced by abiotic processes may mask any isotope signals related to biotic processes. This issue is critical for BIF studies because the large extent of Fe precipitation in seawater, leading to the accumulation of freshly formed 
Fe-oxyhydroxides at the seafloor as likely BIF precursors, may also shift the isotopic composition Ni remaining in seawater.

In a previous study, Wasylenki et al. (2015) suggested that Ni isotopes in BIF should be offset by $\sim-0.35 \%$ relatively to seawater. We further propose that such an offset is likely a minimum value, considering that fractionation up to $\sim-0.77 \%$ is observed during sorption to goethite, regardless of potential kinetic isotope effects. Clearly, further study investigating the preservation of $\mathrm{Ni}$ isotope signatures during $\mathrm{Fe}$-oxyhydroxide recrystallization to hematite and magnetite is warranted in order to directly apply $\mathrm{Ni}$ isotope systematics to the BIF record. Although Wasylenki et al. (2015) showed that there was apparently no isotope fractionation during aging of ferrihydrite and recrystallization to goethite and hematite, they did not determine the proportion of ferrihydrite that has recrystallized, and longer experimental durations as well as heating of the system should be explored to better evaluate the effect of ferrihydrite aging on Ni isotopes. The effect of silica (Eickhoff et al., 2014) and the possibility that it could affect the Ni isotope fractionation factor during BIF formation, has also to be considered when investigating the BIF record.

\section{Summary}

Consistent with previous studies (Wasylenki et al., 2015), we found that $\mathrm{Ni}$ isotopes are readily fractionated towards light $\mathrm{Ni}$ isotopes during adsorption to Fe-oxyhydroxide minerals. Building on that work, we have demonstrated that Ni sorbed to 2-line ferrihydrite is less fractionated than Ni sorbed to goethite with average $\Delta^{60 / 58} \mathrm{Ni}_{\text {min-aq }}$ values of $-0.35 \pm 0.08$ $\%$ and $-0.77 \pm 0.23 \%$, respectively. No difference in $\Delta^{60 / 58} \mathrm{Ni}_{\text {min-aq }}$ values was observed either as a function of $\mathrm{Ni}$ loading or as a function of $\mathrm{pH}$ in both 2-line ferrihydrite and goethite. For both 2-line ferrihydrite and goethite, Ni K-edge EXAFS results indicate that there are no 
measurable changes in $\mathrm{Ni}$ coordination as a function of $\mathrm{pH}$ or final $\mathrm{Ni}$ loading to the mineral. In addition, on the timescale of our experiments there is no evidence that $\mathrm{Ni}$ is structurally incorporated into either mineral. The only difference we found between the two minerals is the lower Ni-Fe coordination number in the second shell of goethite, and we argue that this may account for a larger $\mathrm{Ni}$ isotope fractionation factor $(\sim-0.77 \%)$ to goethite in comparison to 2-line ferrihydrite $(\sim-0.35 \%$ o). Although additional data are required to strengthen the conclusions on kinetic experiments, first results suggest that $\mathrm{Ni}$ concentrations and $\Delta^{60 / 58} \mathrm{Ni}_{\text {min- }}$ aq values do not vary with time, as it would be expected for suspensions at equilibrium. In addition, the $\Delta^{60 / 58} \mathrm{Ni}_{\text {min-aq }}$ values for 2-line ferrihydrite and goethite in the kinetic experiments on average are similar to the $\Delta^{60 / 58} \mathrm{Ni}_{\text {min-aq }}$ values calculated for the $\mathrm{pH}$-dependent and varying initial Ni concentrations experiments suggesting that our experiments are at isotopic equilibrium over a duration of $\sim 24$ hours.

The magnitude of isotope fractionation suggests that $\mathrm{Ni}$ adsorption to $\mathrm{Fe}$ oxyhydroxides is a significant process controlling $\mathrm{Ni}$ isotope abundances in the natural environment. Our study also shows that such $\mathrm{Ni}$ isotope fractionation factors during $\mathrm{Ni}$ adsorption on Fe-oxides are in the same direction and extent as for biological uptake of Ni by methanogens. Hence, these findings provide important insights into the mechanisms of $\mathrm{Ni}$ isotope fractionation in natural environments, as well as cautionary guidelines for interpreting $\mathrm{Ni}$ isotope (bio)signatures in ancient sedimentary rocks. This study underpins the need to further investigate the influence of weathering and soil processes, as well as anthropogenic inputs, on the $\mathrm{Ni}$ isotopic composition of rivers and, in turn, on the mass balance of $\mathrm{Ni}$ isotopes in seawater.

\section{Acknowledgements:}


We thank Marie-Laure Rouget for technical assistance during ICP-MS-quadrupole data acquisition; Yoan Germain for technical assistance in the clean labs; Emmanuel Ponzevera for

801

802

803

804

805

806

807

808

809

810

811

812

\section{Figure captions:}

818 acknowledged.

\section{igure captions:} technical assistance during MC-ICP-MS measurements; Rick Knurr for ICP-MS analyses (Aqueous Geochemistry Lab, University of Minnesota); Dale Brewe, Steve Heald, and Mali Balasubramanian for assistance with Ni K-edge EXAFS data collection (20-BM, Advanced Photon Source, Argonne National Laboratory); Lindsey Briscoe for construction of the $\mathrm{pH}$ stat system; Lee Penn (Department of Chemistry, University of Minnesota) for access to the zeta potential instrumentation, Kyungsoo Yoo (Department of Soil, Water \& Climate) for access to the BET instrumentation; and the Kuehnast Endowment Fund (Department of Soil, Water, and Climate, University of Minnesota) for research support for JVS. We further thank Yves Fouquet and Ewan Pelleter for fruitfull discussions. The powder X-ray diffraction was conducted at the Characterization Facility, University of Minnesota. The Ni K-edge EXAFS data collection was conducted at the Advanced Photon Source (APS), beamline 20-BM. The APS is an Office of Science User Facility operated by the U.S. Department of Energy (DOE) Office of Science by Argonne National Laboratory under contract number DE-AC0206CH11357. Supports from ANR-10-LABX-19-01 LabexMER and Europole Mer are also

Figure 1: Nickel loading to minerals $\left(\mu \mathrm{mol} / \mathrm{m}^{2}\right.$ mineral) as a function of (a) $\mathrm{pH}$ (data from $\mathrm{pH}$-dependent experiments) and (b) initial aqueous concentration of $\mathrm{Ni}(\mu \mathrm{mol} / \mathrm{L})$ (data from varying initial Ni concentration experiments). 
Figure 2: Surface complexation modeling (SCM) using a Constant Capacitance Model (CCM) and experimental data from this study showing percent of Ni sorbed versus solution $\mathrm{pH}$ for (a) 2-line ferrihydrite and (b) goethite. The SCM (bold line) fits the experimental data well (filled circles) for 2-line ferrihydrite (a) while experimental data (filled stars) for goethite deviates from the SCM (dashed line) (b). A possible explanation for this discrepancy was that very little Ni was adsorbed $(<5 \%)$ on the goethite surface, contributing non-negligible uncertainty to the determination of percent $\mathrm{Ni}$ sorbed.

Figure 3: Summary of Ni K-edge EXAFS spectra in k-space for Ni-sorbed 2-line ferrihydrite at $\mathrm{pH} 7.7$ and 8.0. Data are displayed as solid lines, while fits to data are displayed as dashed lines.

Figure 4: Summary of Fourier transformed data (magnitude and imaginary part) and fits for Ni-sorbed 2-line ferrihydrite at $\mathrm{pH} 7.7$ and 8.0. Data are displayed as solid lines, while fits to data are displayed as dashed lines.

Figure 5: Nickel isotope composition (\%o) of minerals (circles) and supernatant solutions (squares) for $\mathrm{pH}$-dependent (pink symbols), variable initial $\mathrm{Ni}$ concentration in solution (brown symbols) and time-dependent experiments (blue symbols) for (a) 2-line ferrihydrite and (b) goethite. The straight black line in the two plots represents the Ni isotope composition of the starting Ni solution $\left(\delta^{60 / 58} \mathrm{Ni}=-0.33 \%\right.$ ). The error bar $(2 \mathrm{sd})$ corresponds the reproducibility of the geostandards ( $\pm 0.06 \%$; see section 2.5 for explanation). Values are consistent between each experiment according to the type of mineral, i.e., $-0.35 \pm 0.08 \%$ for 2-line ferrihydrite and $-0.77 \pm 0.23 \%$ for goethite. The average $\delta^{60 / 58} \mathrm{Ni}$ value for 2 -line ferrihydrite does not take into account the very low Ni-sorbed samples (unfilled datapoints on 
the figure, see main text for explanation). Note also that the $\mathrm{x}$-axis is different for 2-line ferrihydrite and goethite because the range of \%-adsorption is lower for goethite than for 2line ferrihydrite.

Figure 6: $\mathrm{Ni}$ isotope fractionation factors $\left(\Delta^{60 / 58} \mathrm{Ni}\right.$ min-aq $=\delta^{60 / 58} \mathrm{Ni}_{\text {mineral }}-\delta^{60 / 58} \mathrm{Ni}$ aqueous $)$ versus (a) $\mathrm{pH}$ using results from $\mathrm{pH}-$ dependent experiments and (b) final $\mathrm{Ni}$ loading to the mineral ( $\mu \mathrm{mol} / \mathrm{g}$ mineral) for goethite (diamonds) and 2-line ferrihydrite (circles). The error bar (2se) corresponds to the value of $\pm 0.05 \%$ as the highest value determined by error propagation on samples (see section 3.4 for more explanation). The unfilled datapoints in plot (a) correspond to very low $\mathrm{Ni}$-sorbed to 2-line ferrihydrite (see main text for explanation).

Figure 7: Ni isotope fractionation factors $\left(\Delta^{60 / 58} \mathrm{Ni}_{\text {min-aq }}=\delta^{60 / 58} \mathrm{Ni}_{\text {mineral }}-\delta^{60 / 58} \mathrm{Ni}_{\text {aqueous }}\right)$ versus $\%$-adsorption for (a) 2-line ferrihydrite and (b) goethite for each type of experiment. Pink dots are for $\mathrm{pH}$-dependent experiments, brown dots for the variable initial $\mathrm{Ni}$ concentration experiments and blue dots are for the time-dependent experiments. The unfilled red datapoints in plot (a) (2-line ferrihydrite) correspond to very low Ni-sorbed samples (see main text for explanation).

\section{Table captions:}

Table 1: Sample information, summary of experimental conditions, Ni loading to the mineral and $\mathrm{Ni}$ isotope composition (\%o) of mineral phases and supernatant solutions for $\mathrm{pH}$ dependent experiments, variable Ni concentration experiments. Non-filled symbols correspond to the very low sorbed Ni samples (see text for discussion). 
873 Table 2: Sample information, summary of experimental conditions, Ni loading to the mineral

874 and $\mathrm{Ni}$ isotope composition (\%) of mineral phases and supernatant solutions for time-

875 dependent experiments.

876

877 Table 3: Summary of Ni K-edge EXAFS fit parameters.

878

879 
Arai, Y., 2008. Spectroscopic Evidence for Ni(II) Surface Speciation at the Iron Oxyhydroxides-Water Interface. Environmental Science \& Technology, 42(4): 1151-1156.

Balistrieri, L.S., Borrok, D.M., Wanty, R.B., Ridley, W.I., 2008. Fractionation of Cu and Zn isotopes during adsorption onto amorphous Fe(III) oxyhydroxide: Experimental mixing of acid rock drainage and ambient river water. Geochimica Et Cosmochimica Acta, 72(2): 311 328.

Barling, J., Anbar, A.D., 2004. Molybdenum isotope fractionation during adsorption by manganese oxides. Earth and Planetary Science Letters, 217(3-4): 315-329.

Barrow, N.J., Brümmer, G.W., Fischer, L., 2012. Rate of desorption of eight heavy metals from goethite and its implications for understanding the pathways for penetration. European Journal of Soil Science, 63(3): 389-398.

Beard, B.L. et al., 2010. Iron isotope fractionation between aqueous ferrous iron and goethite. Earth and Planetary Science Letters, 295(1-2): 241-250.

894

895

896

897

898

899

900

901

902

903

904

905

906

907

908

909

910

911

912

913

914

915

Bekker, A. et al., 2010. Iron Formation: The Sedimentary Product of a Complex Interplay among Mantle, Tectonic, Oceanic, and Biospheric Processes. Economic Geology, 105(3): 467-508.

Bruemmer, G.W., Gerth, J., Tiller, K.G., 1988. Reaction kinetics of the adsorption and desorption of nickel, zinc and cadmium by goethite. I. Adsorption and diffusion of metals. Journal of Soil Science, 39(1): 37-52.

Bruland, K.W., 1980. Oceanographic distributions of Cadmium, Zinc, Nickel, and Copper in the North Pacific. Earth and Planetary Science Letters, 47(2): 176-198.

Brümmer, G.W., Barrow, N.J., Fischer, L., 2013. Effect of porosity of goethite on the sorption of six heavy metal ions. European Journal of Soil Science, 64(6): 805-813.

Butt, C.R.M., Cluzel, D., 2013. Nickel Laterite Ore Deposits: Weathered Serpentinites. Elements, 9(2): 123-128.

Callender, E., 2014. Heavy Metals in the Environment - Historical Trends A2 - Holland, Heinrich D. In: Turekian, K.K. (Ed.), Treatise on Geochemistry (Second Edition). Elsevier, Oxford, pp. 59-89.

Cameron, V., Vance, D., 2014. Heavy nickel isotope compositions in rivers and the oceans. Geochimica Et Cosmochimica Acta, 128(0): 195-211.

Cameron, V., Vance, D., Archer, C., House, C.H., 2009. A biomarker based on the stable isotopes of nickel. Proceedings of the National Academy of Sciences of the United States of America, 106(27): 10944-10948.

Carvalho-E-Silva, M.L. et al., 2003. Incorporation of Ni into natural goethite: An investigation by X-ray absorption spectroscopy. American Mineralogist, 88(5): 876-882. 
Cismasu, A.C., Levard, C., Michel, F.M., Brown Jr, G.E., 2013. Properties of impuritybearing ferrihydrite II: Insights into the surface structure and composition of pure, Al- and Sibearing ferrihydrite from $\mathrm{Zn}$ (II) sorption experiments and $\mathrm{Zn} \mathrm{K}$-edge X-ray absorption spectroscopy. Geochimica et Cosmochimica Acta, 119(0): 46-60.

Cornell, R.M., Giovanoli, R., Schneider, W., 1992. The effect of Nickel on the conversion of amorphous iron(III) hydroxide into more crystalline iron-oxides in alkaline media. Journal of Chemical Technology and Biotechnology, 53(1): 73-79.

Cornell, R.M., Schwertmann, U., 1979. Influence of organic-anions on the crystallization of ferrihydrite. Clays and Clay Minerals, 27(6): 402-410.

Cornell, R.M., Schwertmann, U., 2003. The Iron Oxides: Structure, Properties, Reactions, Occurrences and Uses. Wiley, New York, 603 pp.

Davis, J.A., Kent, D.B., 1990. Surface complexation modeling in aqueous geochemistry. Mineral-Water Interface Geochemistry, 23.

Dublet, G. et al., 2012. Ni speciation in a New Caledonian lateritic regolith: A quantitative Xray absorption spectroscopy investigation. Geochimica et Cosmochimica Acta, 95(0): 119133.

Dublet, G. et al., 2014. XAS evidence for Ni sequestration by siderite in a lateritic Ni-deposit from New Caledonia, American Mineralogist, pp. 225.

Dzombak, D.A., Morel, F.M.M., 1990. Surface complexation modeling : hydrous ferric oxide. Wiley, New York.

Eickhoff, M. et al., 2014. Nickel partitioning in biogenic and abiogenic ferrihydrite: The influence of silica and implications for ancient environments. Geochimica et Cosmochimica Acta, 140(0): 65-79.

Ellis, A.S., Johnson, T.M., Bullen, T.D., 2004. Using Chromium Stable Isotope Ratios To Quantify Cr(VI) Reduction: Lack of Sorption Effects. Environmental Science \& Technology, 38(13): 3604-3607.

Essington, M.E., 2003. Surface chemistry and adsorption reactions, Soil and water chemistry. CRC Press LLC, Boca Raton, FL.

Fischer, L., Brümmer, G.W., Barrow, N.J., 2007. Observations and modelling of the reactions of 10 metals with goethite: adsorption and diffusion processes. European journal of soil science, 58(6): 1304-1315.

Frierdich, A.J., Beard, B.L., Reddy, T.R., Scherer, M.M., Johnson, C.M., 2014. Iron isotope fractionation between aqueous Fe(II) and goethite revisited: New insights based on a multidirection approach to equilibrium and isotopic exchange rate modification. Geochimica et Cosmochimica Acta, 139(0): 383-398.

Frierdich, A.J., Luo, Y., Catalano, J.G., 2011. Trace element cycling through iron oxide minerals during redox-driven dynamic recrystallization. Geology, 39(11): 1083-1086. 
Gaillardet, J., Viers, J., Dupré, B., 2014. Trace Elements in River Waters. In: Turekian, H.D.H.K. (Ed.), Treatise on Geochemistry (Second Edition). Elsevier, Oxford, pp. 195-235.

Gall, L. et al., 2013. Nickel isotopic compositions of ferromanganese crusts and the constancy of deep ocean inputs and continental weathering effects over the Cenozoic. Earth and Planetary Science Letters, 375(0): 148-155.

Goldberg, T., Archer, C., Vance, D., Poulton, S.W., 2009. Mo isotope fractionation during adsorption to Fe (oxyhydr)oxides. Geochimica et Cosmochimica Acta, 73(21): 6502-6516.

Gueguen, B., Rouxel, O., Ponzevera, E., Bekker, A., Fouquet, Y., 2013. Nickel Isotope Variations in Terrestrial Silicate Rocks and Geological Reference Materials Measured by MC-ICP-MS. Geostandards and Geoanalytical Research, 37(3): 297-317.

Gueguen, B. et al., 2016. Comparative geochemistry of four ferromanganese crusts from the Pacific Ocean and significance for the use of $\mathrm{Ni}$ isotopes as paleoceanographic tracers. Geochimica et Cosmochimica Acta.

Hayes, K.F., Redden, G., Ela, W., Leckie, J.O., 1991. Surface complexation models: An evaluation of model parameter estimation using FITEQL and oxide mineral titration data. Journal of Colloid and Interface Science, 142(2): 448-469.

Hofmann, A. et al., 2014. Comparing orthomagmatic and hydrothermal mineralization models for komatiite-hosted nickel deposits in Zimbabwe using multiple-sulfur, iron, and nickel isotope data. Mineralium Deposita, 49(1): 75-100.

Icopini, G.A., Anbar, A.D., Ruebush, S.S., Tien, M., Brantley, S.L., 2004. Iron isotope fractionation during microbial reduction of iron: The importance of adsorption. Geology, 32(3): 205-208.

Jiskra, M., Wiederhold, J.G., Bourdon, B., Kretzschmar, R., 2012. Solution Speciation Controls Mercury Isotope Fractionation of $\mathrm{Hg}$ (II) Sorption to Goethite. Environmental Science \& Technology, 46(12): 6654-6662.

Juillot, F. et al., 2008. Zn isotopic fractionation caused by sorption on goethite and 2-Lines ferrihydrite. Geochimica Et Cosmochimica Acta, 72(19): 4886-4900.

Kashiwabara, T., Takahashi, Y., Tanimizu, M., 2009. A XAFS study on the mechanism of isotopic fractionation of molybdenum during its adsorption on ferromanganese oxides. GEOCHEMICAL JOURNAL, 43(6): e31-e36.

Kelly, S.D., Hesterberg, D., Ravel, B., 2008. Analysis of Soils and Minerals Using X-ray Absorption Spectroscopy, Methods of Soil Analysis. Soil Science Society of America, Madison, WI.

Konhauser, K.O. et al., 2009. Oceanic nickel depletion and a methanogen famine before the Great Oxidation Event. Nature, 458(7239): 750-754.

Konhauser, K.O. et al., 2015. The Archean Nickel Famine Revisited. Astrobiology, 15(10): 804-815. 
Koschinsky, A., Halbach, P., 1995. Sequential leaching of marine ferromanganese precipitates: Genetic implications. Geochimica et Cosmochimica Acta, 59(24): 5113-5132.

Krishnaswami, S., 1976. Authigenic transition elements in Pacific pelagic clays. Geochimica Et Cosmochimica Acta, 40(4): 425-434.

Leinen, M., 1987. The origin of paleochemical signatures in North Pacific pelagic clays: Partitioning experiments. Geochimica et Cosmochimica Acta, 51(2): 305-319.

Li, X.F., Liu, Y., 2010. First-principles study of Ge isotope fractionation during adsorption onto Fe(III)-oxyhydroxide surfaces. Chemical Geology, 278(1-2): 15-22.

Manceau, A., Calas, G., 1985. Heterogeneous distribution of nickel in hydrous silicates from New Caledonia ore deposits. American Mineralogist, 70(5-6): 549-558.

Manceau, A., Drits, V.A., 1993. Local structure of ferrihydrite and feroxyhite by EXAFS spectroscopy. Clay Minerals, 28(2): 165-184.

Manceau, A., Gates, W.P., 1997. Surface structural model for ferrihydrite. Clays and Clay Minerals, 45(3): 448-460.

Manceau, A., Llorca, S., Calas, G., 1987. Crystal chemistry of cobalt and nickel in lithiophorite and asbolane from New Caledonia. Geochimica Et Cosmochimica Acta, 51(1): 105-113.

Manceau, A. et al., 2000. Crystal chemistry of trace elements in natural and synthetic goethite. Geochimica et Cosmochimica Acta, 64(21): 3643-3661.

Manceau, A. et al., 2002. Deciphering Ni sequestration in soil ferromanganese nodules by combining X-ray fluorescence, absorption, and diffraction at micrometer scales of resolution. American Mineralogist, 87(10): 1494-1499.

Martin, J.M., Meybeck, M., 1979. Elemental mass-balance of material carried by major world rivers. Marine Chemistry, 7(3): 173-206.

Mikutta, C. et al., 2009. Iron isotope fractionation and atom exchange during sorption of ferrous iron to mineral surfaces. Geochimica et Cosmochimica Acta, 73(7): 1795-1812.

Mitchell, K., Couture, R.-M., Johnson, T.M., Mason, P.R.D., Van Cappellen, P., 2013. Selenium sorption and isotope fractionation: Iron(III) oxides versus iron(II) sulfides. Chemical Geology, 342: 21-28.

Morel, F.M.M., Price, N.M., 2003. The Biogeochemical Cycles of Trace Metals in the Oceans. Science, 300(5621): 944.

Mouvet, C., Bourg, A.C.M., 1983. Speciation (including adsorbed species) of copper, lead, nickel and zinc in the Meuse River: Observed results compared to values calculated with a chemical equilibrium computer program. Water Research, 17(6): 641-649.

Navrotsky, A., Mazeina, L., Majzlan, J., 2008. Size-Driven Structural and Thermodynamic Complexity in Iron Oxides. Science, 319(5870): 1635-1638. 
Peacock, C.L., Sherman, D.M., 2007a. Sorption of Ni by birnessite: Equilibrium controls on Ni in seawater. Chemical Geology, 238(1-2): 94-106.

Peacock, C.L., Sherman, D.M., 2007b. Crystal-chemistry of Ni in marine ferromanganese crusts and nodules. American Mineralogist, 92(7): 1087-1092.

Peña, J., Kwon, K.D., Refson, K., Bargar, J.R., Sposito, G., 2010. Mechanisms of nickel sorption by a bacteriogenic birnessite. Geochimica et Cosmochimica Acta, 74(11): 30763089.

Pokrovsky, O.S., Galy, A., Schott, J., Pokrovski, G.S., Mantoura, S., 2014. Germanium isotope fractionation during Ge adsorption on goethite and its coprecipitation with $\mathrm{Fe}$ oxy(hydr)oxides. Geochimica et Cosmochimica Acta, 131(0): 138-149.

Pokrovsky, O.S., Viers, J., Emnova, E.E., Kompantseva, E.I., Freydier, R., 2008. Copper isotope fractionation during its interaction with soil and aquatic microorganisms and metal oxy(hydr)oxides: Possible structural control. Geochimica et Cosmochimica Acta, 72(7): 17421757.

Pokrovsky, O.S., Viers, J., Freydier, R., 2005. Zinc stable isotope fractionation during its adsorption on oxides and hydroxides. Journal of Colloid and Interface Science, 291(1): 192200.

Porter, S.J., Selby, D., Cameron, V., 2014. Characterising the nickel isotopic composition of organic-rich marine sediments. Chemical Geology, 387(0): 12-21.

Price, N.M., Morel, F.M.M., 1991. Colimitation of phytoplankton growth by Nickel and Nitrogen. Limnology and Oceanography, 36(6): 1071-1077.

Quantin, C., Ettler, V., Garnier, J., Šebek, O., 2008. Sources and extractibility of chromium and nickel in soil profiles developed on Czech serpentinites. Comptes Rendus Geoscience, 340(12): 872-882.

Ratié, G. et al., 2015. Nickel isotope fractionation during tropical weathering of ultramafic rocks. Chemical Geology, 402(0): 68-76.

Ravel, B., Newville, M., 2005. ATHENA, ARTEMIS, HEPHAESTUS: data analysis for Xray absorption spectroscopy using IFEFFIT. Journal of Synchrotron Radiation, 12: 537-541.

Rehkämper, M. et al., 2002. Thallium isotope variations in seawater and hydrogenetic, diagenetic, and hydrothermal ferromanganese deposits. Earth and Planetary Science Letters, 197(1-2): 65-81.

Schauble, E.A., 2004. Applying Stable Isotope Fractionation Theory to New Systems. Reviews in Mineralogy and Geochemistry, 55(1): 65-111.

Schwertmann, U., Stanjek, H., Becher, H.-H., 2004. Long-term in vitro transformation of 2line ferrihydrite to goethite/hematite at 4, 10, 15 and $25^{\circ} \mathrm{C}$. Clay Minerals, 39(4): 433-438.

Sclater, F.R., Boyle, E., Edmond, J.M., 1976. On the marine geochemistry of nickel. Earth and Planetary Science Letters, 31(1): 119-128. 
Siebert, C., Nagler, T.F., Kramers, J.D., 2001. Determination of molybdenum isotope fractionation by double-spike multicollector inductively coupled plasma mass spectrometry. Geochemistry Geophysics Geosystems, 2: 1032.

Siebert, C., Nagler, T.F., von Blanckenburg, F., Kramers, J.D., 2003. Molybdenum isotope records as a potential new proxy for paleoceanography. Earth and Planetary Science Letters, 211(1-2): 159-171.

Snodgrass, W.J., 1980. Distribution and behavior of nickel in the aquatic environment. New York, John Wiley \& Sons, pp. 203-274.

Soper, A.K., Neilson, G.W., Enderby, J.E., Howe, R.A., 1977. A neutron diffraction study of hydration effects in aqueous solutions. Journal of Physics C: Solid State Physics, 10(11): 1793.

Toner, B.M. et al., 2012. Mineralogy of iron microbial mats from loihi seamount. Frontiers in microbiology, 3 .

Turekian, K.K., 1977. The fate of metals in oceans. Geochimica Et Cosmochimica Acta, 41(8): 1139-1144.

Valeton, I., Biermann, M., Reche, R., Rosenberg, F., 1987. Genesis of nickel laterites and bauxites in greece during the jurassic and cretaceous, and their relation to ultrabasic parent rocks. Ore Geology Reviews, 2(4): 359-404.

Vasyukova, E.V. et al., 2010. Trace elements in organic- and iron-rich surficial fluids of the boreal zone: Assessing colloidal forms via dialysis and ultrafiltration. Geochimica et Cosmochimica Acta, 74(2): 449-468.

Villalobos, M., Trotz, M.A., Leckie, J.O., 2003. Variability in goethite surface site density: evidence from proton and carbonate sorption. Journal of Colloid and Interface Science, 268(2): 273-287.

Wasylenki, L.E., Howe, H.D., Spivak-Birndorf, L.J., Bish, D.L., 2015. Ni isotope fractionation during sorption to ferrihydrite: Implications for $\mathrm{Ni}$ in banded iron formations. Chemical Geology, 400(0): 56-64.

Wasylenki, L.E., Swihart, J.W., Romaniello, S.J., 2014. Cadmium isotope fractionation during adsorption to Mn oxyhydroxide at low and high ionic strength. Geochimica et Cosmochimica Acta, 140(0): 212-226.

Wasylenki, L.E. et al., 2011. The molecular mechanism of Mo isotope fractionation during adsorption to birnessite. Geochimica Et Cosmochimica Acta, 75(17): 5019-5031.

Waychunas, G.A., Fuller, C.C., Davis, J.A., 2002. Surface complexation and precipitate geometry for aqueous $\mathrm{Zn}$ (II) sorption on ferrihydrite I: X-ray absorption extended fine structure spectroscopy analysis. Geochimica et Cosmochimica Acta, 66(7): 1119-1137.

Webb, S.M., 2005. SIXpack: a graphical user interface for XAS analysis using IFEFFIT. Physica Scripta, 2005(T115): 1011. 
1100 Wu, L., Percak-Dennett, E.M., Beard, B.L., Roden, E.E., Johnson, C.M., 2012. Stable iron 1101 isotope fractionation between aqueous Fe(II) and model Archean ocean Fe-Si coprecipitates 1102 and implications for iron isotope variations in the ancient rock record. Geochimica Et 1103 Cosmochimica Acta, 84(0): 14-28.

1104 Wu, L.L., Beard, B.L., Roden, E.E., Johnson, C.M., 2011. Stable Iron Isotope Fractionation 1105 Between Aqueous Fe(II) and Hydrous Ferric Oxide. Environmental Science \& Technology, 1106 45(5): 1847-1852.

1107 Xu, Y., Axe, L., Yee, N., Dyer, J.A., 2006. Bidentate Complexation Modeling of Heavy 1108 Metal Adsorption and Competition on Goethite. Environmental Science \& Technology, 40(7): 1109 2213-2218. 
Table 1: Sample information, summary of experimental conditions, Ni loading to the mineral and Ni isotope composition (\%) of mineral phases and supernatant solutions for pH-dependent and variable Ni experiments.

\begin{tabular}{|c|c|c|c|c|c|c|c|c|c|c|c|c|c|c|}
\hline Mineral & Sample name & Type of experiment & $\mathrm{pH}$ & $\begin{array}{c}{[\mathrm{Ni}]_{\mathrm{aq}}^{\text {initial }}} \\
(\mu \mathrm{mol} / \mathrm{L})\end{array}$ & $\begin{array}{c}\text { Final loading to } \\
\text { mineral }(\mu \mathrm{mol} \\
\mathrm{Ni} / \mathrm{g})^{\mathrm{c}}\end{array}$ & $\begin{array}{c}\text { Final loading to } \\
\text { mineral }(\mu \mathrm{mol} \\
\left.\mathrm{Ni} / \mathrm{m}^{2}\right)^{c}\end{array}$ & $\begin{array}{l}\% \text { of } \mathrm{Ni} \\
\text { sorption }\end{array}$ & $\delta^{60 / 58} \mathrm{Ni}_{\text {mineral }}$ & $2 s e^{e}$ & $\delta^{60 / 58} \mathrm{Ni}_{\text {aqueous }}$ & 2 se & $\Delta^{60 / 58} \mathrm{Ni}_{\text {min-aq }}{ }^{f}$ & $2 \mathbf{s e}^{g}$ & Mass balance $(\%)$ \\
\hline 2-line Ferrihydrite ${ }^{a}$ & Fh-pH-01 & pH dependent & 5.0 & 170 & 1.99 & 0.02 & 1.2 & -0.36 & 0.02 & -0.32 & 0.03 & -0.03 & 0.03 & -0.32 \\
\hline 2-line Ferrihydrite & Fh-pH-02 & pH dependent & 6.0 & 170 & 4.77 & 0.04 & 2.9 & -0.47 & 0.02 & -0.35 & 0.03 & -0.12 & 0.04 & -0.35 \\
\hline 2-line Ferrihydrite & Fh-pH-03 & $\mathrm{pH}$ dependent & 7.0 & 170 & 38.21 & 0.32 & 23.4 & -0.57 & 0.02 & -0.30 & 0.03 & -0.27 & 0.04 & -0.36 \\
\hline 2-line Ferrihydrite & Fh-pH-04 & $\mathrm{pH}$ dependent & 7.7 & 170 & 66.61 & 0.56 & 41.7 & -0.52 & 0.02 & -0.15 & 0.03 & -0.37 & 0.04 & -0.31 \\
\hline 2-line Ferrihydrite & Fh-pH-05* & pH dependent & 8.0 & 170 & 73.81 & 0.62 & 45.3 & -0.55 & 0.02 & -0.17 & 0.04 & -0.38 & 0.05 & -0.34 \\
\hline 2-line Ferrihydrite & Fh-C-06 & Varying initial [Ni] & 7.7 & 17 & 12.97 & 0.11 & 78.1 & -0.41 & 0.02 & -0.02 & 0.04 & -0.39 & 0.04 & -0.33 \\
\hline 2-line Ferrihydrite & Fh-C- $07^{*}$ & Varying initial [Ni] & 7.7 & 85 & 38.64 & 0.32 & 46.8 & -0.51 & 0.02 & -0.18 & 0.04 & -0.32 & 0.04 & -0.34 \\
\hline 2-line Ferrihydrite & Fh-C- $08^{*}$ & Varying initial [Ni] & 7.7 & 170 & 41.31 & 0.35 & 24.8 & -0.56 & 0.02 & -0.22 & 0.04 & -0.34 & 0.04 & -0.30 \\
\hline 2-line Ferrihydrite & Fh-C-09* & Varying initial [Ni] & 7.7 & 341 & 131.24 & 1.10 & 39.2 & -0.54 & 0.03 & -0.13 & 0.04 & -0.40 & 0.05 & -0.29 \\
\hline 2-line Ferrihydrite & Fh-C- $10^{*}$ & Varying initial $[\mathrm{Ni}]$ & 7.7 & 426 & 203.14 & 1.71 & 49.8 & -0.53 & 0.03 & -0.28 & 0.04 & -0.24 & 0.05 & -0.40 \\
\hline Goethite $^{\mathrm{b}}$ & Goe-pH-01 & $\mathrm{pH}$ dependent & 5.0 & 170 & 1.00 & 0.04 & 0.6 & -1.00 & 0.03 & -0.30 & 0.03 & -0.70 & 0.04 & -0.31 \\
\hline Goethite & Goe-pH-02 & $\mathrm{pH}$ dependent & 6.0 & 170 & 1.33 & 0.05 & 0.8 & -1.13 & 0.03 & -0.25 & 0.04 & -0.88 & 0.05 & -0.25 \\
\hline Goethite & Goe-pH-03 & $\mathrm{pH}$ dependent & 8.0 & 170 & 7.17 & 0.28 & 4.3 & -1.19 & 0.03 & -0.23 & 0.03 & -0.96 & 0.05 & -0.27 \\
\hline Goethite & Goe-C-04 & Varying initial [Ni] & 7.7 & 170 & 15.96 & 0.63 & 9.5 & -1.08 & 0.02 & -0.27 & 0.04 & -0.80 & 0.04 & -0.35 \\
\hline Goethite & Goe-C-05 & Varying initial $[\mathrm{Ni}]$ & 7.7 & 341 & 17.56 & 0.69 & 19.3 & -1.15 & 0.02 & -0.12 & 0.04 & -1.03 & 0.04 & -0.35 \\
\hline Goethite & Goe-C- $06^{*}$ & Varying initial $[\mathrm{Ni}]$ & 7.7 & 426 & 33.86 & 1.33 & 7.9 & -1.07 & 0.02 & -0.29 & 0.03 & -0.78 & 0.04 & -0.35 \\
\hline Ni standard solution & - & - & - & - & - & - & - & - & - & -0.32 & 0.03 & - & - & - \\
\hline $\mathrm{Ni}$ standard solution & - & - & - & - & - & - & - & - & - & -0.34 & 0.03 & - & - & - \\
\hline $\mathrm{Ni}$ standard solution & - & - & - & - & - & - & - & - & - & -0.30 & 0.03 & - & - & - \\
\hline $\mathrm{Ni}$ standard solution & - & - & - & - & - & - & - & - & - & -0.35 & 0.06 & - & - & - \\
\hline $\begin{array}{c}\text { Average } \mathrm{Ni} \\
\text { standard solution }^{\mathrm{h}}\end{array}$ & - & - & - & - & - & - & - & - & - & -0.33 & $0.05(2 \mathrm{sd})$ & - & - & - \\
\hline Nod-A-1 & - & - & - & - & - & - & - & - & - & 1.06 & 0.02 & - & - & - \\
\hline Nod-A-1' & - & - & - & - & - & - & - & - & - & 1.01 & 0.03 & - & - & - \\
\hline Nod-A-1 ${ }^{\mathrm{i}}$ & - & - & - & - & - & - & - & - & - & 1.05 & 0.04 & - & - & - \\
\hline Nod-P-1' & - & - & - & - & - & - & - & - & - & 0.30 & 0.03 & - & - & - \\
\hline Nod-P-1 & - & - & - & - & - & - & - & - & - & 0.35 & 0.04 & - & - & - \\
\hline Nod-P-1 ${ }^{1}$ & - & - & - & - & - & - & - & - & - & 0.34 & 0.03 & - & - & - \\
\hline Nod-P-1 ${ }^{i}$ & - & - & - & - & - & - & - & - & - & 0.32 & 0.03 & - & - & - \\
\hline
\end{tabular}

Samples for which Ni K-edge EXAFS data were collected.

2-line ferrihydrite $(0.014 \mathrm{~mol} \mathrm{Fe} / \mathrm{g}$ dry mineral)

Goethite $(0.015 \mathrm{~mol}$ Fe/g dry mineral)

${ }^{c}$ Final loading corresponds to the amount of $\mathrm{Ni}$ per gram or $\mathrm{m}^{2}$ of mineral in the reactor. The amount of mineral added per reactor measured was $\sim 0.15 \mathrm{~g}$.

${ }^{\mathrm{d}} \mathrm{Ni}$ sorbed fractions (\%) were determined by mass balance using measured amount of $\mathrm{Ni}$ in solution and adsorbed onto minerals.

2 se corresponds to the two standard error of the mean determined on the 50 measurement cycles on the MC-ICP-MS for each sample (see text for explanation).

${ }^{f} T$ The difference in isotopic composition between the mineral and the supernatant solution is expressed as $\Delta^{60158} \mathrm{Ni}_{\text {min-aq }}=\delta^{60158} \mathrm{Ni}_{\text {mineral }}-\delta^{60158} \mathrm{Ni}_{\text {aqueous. }}$. This value corresponds to the fractionation factor during $\mathrm{Ni}$ adsorption on the mineral surface. A two-standard error was

determined for this value by error propagation.

$\Delta^{60158} \mathrm{Ni}_{\text {miraa }}$ values $\left(2 \mathrm{se}=\sqrt{ }\left(\left(2 \mathrm{se}_{\text {mineral }}\right)^{2}+\left(2 \mathrm{se}_{\text {aqueous }}\right)^{2}\right)\right)$.

列

Nod-A-1 and Nod-P-1 are duplicates of USGS geostandards measured for monitoring the reproducibility of the data. 
Table 2: Sample information, summary of experimental conditions, Ni loading to the mineral and Ni isotope composition (\%) of mineral phases and supernatant solutions for the time-dependent experiments.

\begin{tabular}{|c|c|c|c|c|c|c|c|c|c|c|c|c|c|c|}
\hline Mineral $^{*}$ & $\begin{array}{l}\text { Sample } \\
\text { name }\end{array}$ & $\begin{array}{c}\text { Duration of } \\
\text { experiment (hours) }\end{array}$ & pH & $\begin{array}{l}{\left[\mathrm{Ni}_{\mathrm{aq}}{ }_{\mathrm{aq}}^{\text {itial }}\right.} \\
(\mu \mathrm{mol} / \mathrm{L})\end{array}$ & \begin{tabular}{|c|} 
Final \\
loading to \\
mineral \\
$(\mu \mathrm{mol}$ \\
$\mathrm{Ni} / \mathrm{g})$
\end{tabular} & $\begin{array}{c}\text { Final } \\
\text { loading to } \\
\text { mineral } \\
(\mu \mathrm{mol} \\
\left.\mathrm{Ni} / \mathrm{m}^{2}\right)\end{array}$ & $\begin{array}{l}\% \text { of } \mathrm{Ni} \\
\text { sorption }\end{array}$ & $\delta^{60 / 58} \mathrm{Ni}_{\text {mineral }}$ & $2 \mathrm{se}$ & $\delta^{60 / 58} \mathrm{Ni}_{\text {aqueous }}$ & $2 \mathrm{se}$ & $\Delta^{60 / 58} \mathrm{Ni}_{\text {min-aq }}$ & $2 \mathrm{se}$ & $\begin{array}{c}\text { Mass } \\
\text { balance } \\
(\% \circ)\end{array}$ \\
\hline Goethite & Goe-T-07 & 18 & 7.7 & 170 & 41.0 & 1.6 & 22.3 & -0.98 & 0.05 & -0.21 & 0.06 & -0.77 & 0.07 & -0.38 \\
\hline Goethite & Goe-T-08 & 20 & 7.7 & 170 & 41.7 & 1.6 & 22.0 & -0.96 & 0.05 & -0.19 & 0.05 & -0.77 & 0.07 & -0.36 \\
\hline Goethite & Goe-T-09 & 22 & 7.7 & 170 & 42.2 & 1.7 & 22.6 & -0.98 & 0.08 & -0.26 & 0.03 & -0.72 & 0.08 & -0.42 \\
\hline Goethite & Goe-T-10 & 23 & 7.7 & 170 & 42.5 & 1.7 & 22.0 & -0.98 & 0.04 & -0.24 & 0.04 & -0.74 & 0.05 & -0.41 \\
\hline Goethite & Goe-T-11 & 18 & 7.7 & 426 & 65.3 & 2.6 & 17.2 & -0.88 & 0.06 & -0.25 & 0.04 & -0.62 & 0.07 & -0.36 \\
\hline Goethite & Goe-T-12 & 20 & 7.7 & 426 & 50.6 & 2.0 & 14.4 & -0.99 & 0.06 & -0.27 & 0.03 & -0.73 & 0.07 & -0.37 \\
\hline Goethite & Goe-T-13 & 22 & 7.7 & 426 & 56.7 & 2.2 & 15.6 & -0.94 & 0.03 & -0.29 & 0.06 & -0.65 & 0.07 & -0.39 \\
\hline Goethite & Goe-T-14 & 23 & 7.7 & 426 & 51.6 & 2.0 & 12.9 & -0.97 & 0.05 & -0.29 & 0.07 & -0.68 & 0.08 & -0.38 \\
\hline 2-line Ferrihydrite & Fh-T-11 & 19 & 7.7 & 170 & 225.2 & 1.9 & 92.4 & -0.36 & 0.04 & 0.00 & 0.05 & -0.36 & 0.06 & -0.33 \\
\hline 2-line Ferrihydrite & Fh-T-12 & 20 & 7.7 & 170 & 224.5 & 1.9 & 92.9 & -0.37 & 0.04 & -0.02 & 0.03 & -0.35 & 0.05 & -0.35 \\
\hline 2-line Ferrihydrite & Fh-T-13 & 22 & 7.7 & 170 & 223.5 & 1.9 & 93.2 & -0.36 & 0.02 & -0.01 & 0.04 & -0.35 & 0.04 & -0.34 \\
\hline 2-line Ferrihydrite & Fh-T-14 & 23 & 7.7 & 170 & 322.7 & 2.7 & 95.0 & -0.39 & 0.05 & -0.05 & 0.03 & -0.34 & 0.05 & -0.38 \\
\hline 2-line Ferrihydrite & Fh-T-15 & 19 & 7.7 & 426 & 444.4 & 3.7 & 91.5 & -0.41 & 0.04 & -0.03 & 0.05 & -0.37 & 0.06 & -0.37 \\
\hline 2-line Ferrihydrite & Fh-T-16 & 20 & 7.7 & 426 & 443.1 & 3.7 & 91.5 & -0.43 & 0.04 & -0.05 & 0.05 & -0.38 & 0.06 & -0.40 \\
\hline 2-line Ferrihydrite & Fh-T-17 & 22 & 7.7 & 426 & 392.9 & 3.3 & 85.7 & -0.37 & 0.02 & -0.05 & 0.04 & -0.32 & 0.04 & -0.33 \\
\hline 2-line Ferrihydrite & Fh-T-18 & 23 & 7.7 & 426 & 443.1 & 3.7 & 91.3 & -0.42 & 0.06 & -0.06 & 0.01 & -0.36 & 0.06 & -0.39 \\
\hline
\end{tabular}

*See Table 1 for footnotes. 
Table 3: Summary of Ni EXAFS fit parameters.

\begin{tabular}{|c|c|c|c|c|c|c|c|c|}
\hline Sample Name & Path & $\mathrm{CN}$ & $\mathbf{R}(\mathbf{A})$ & $\sigma^{2}\left(\AA^{2}\right)$ & $\Delta \mathrm{E}_{0}(\mathrm{eV})$ & $\chi$ & $\operatorname{Red} \chi^{2}$ & R-factor \\
\hline Fh-C-10 & $\begin{array}{l}\mathrm{Ni}-\mathrm{O} \\
\mathrm{Ni}-\mathrm{Fe} \\
\mathrm{Ni}-\mathrm{Fe} \\
\end{array}$ & $\begin{array}{l}5.945 \pm 0.644 \\
1.618 \pm 0.405 \\
0.574 \pm 0.144 \\
\end{array}$ & $\begin{array}{l}2.050 \pm 0.0078 \\
3.102 \pm 0.0159 \\
3.561 \pm 0.0488 \\
\end{array}$ & $\begin{array}{l}0.0069 \pm 0.0011 \\
0.0079 \pm 0.0017 \\
0.0079 \pm 0.0017\end{array}$ & $-5.273 \pm 1.233$ & $0.8088 \pm 0.1304$ & 23.39 & 0.0145 \\
\hline Fh-C-09 & $\begin{array}{l}\mathrm{Ni}-\mathrm{O} \\
\mathrm{Ni}-\mathrm{Fe} \\
\mathrm{Ni}-\mathrm{Fe} \\
\end{array}$ & $\begin{array}{c}6.543 \pm .0760 \\
1.404 \pm 0.351 \\
0.894 \pm 0.224 \\
\end{array}$ & $\begin{array}{l}2.052 \pm 0.0087 \\
3.096 \pm 0.0187 \\
3.596 \pm 0.0347 \\
\end{array}$ & $\begin{array}{l}0.0082 \pm 0.0013 \\
0.0079 \pm 0.0020 \\
0.0079 \pm 0.0020\end{array}$ & $-4.844 \pm 1.275$ & $0.7022 \pm 0.1250$ & 10.69 & 0.0166 \\
\hline Fh-C-08 & $\begin{array}{l}\mathrm{Ni}-\mathrm{O} \\
\mathrm{Ni}-\mathrm{Fe} \\
\mathrm{Ni}-\mathrm{Fe} \\
\end{array}$ & $\begin{array}{l}6.507 \pm 0.754 \\
1.681 \pm 0.420 \\
0.478 \pm 0.120 \\
\end{array}$ & $\begin{array}{l}2.050 \pm 0.0087 \\
3.102 \pm 0.0161 \\
3.593 \pm 0.0618 \\
\end{array}$ & $\begin{array}{l}0.0084 \pm 0.0013 \\
0.0080 \pm 0.0019 \\
0.0080 \pm 0.0019 \\
\end{array}$ & $-4.972 \pm 1.275$ & $0.8407 \pm 0.1340$ & 10.09 & 0.0162 \\
\hline Fh-C-07 & $\begin{array}{l}\mathrm{Ni}-\mathrm{O} \\
\mathrm{Ni}-\mathrm{Fe} \\
\mathrm{Ni}-\mathrm{Fe} \\
\end{array}$ & $\begin{array}{l}6.441 \pm 0.931 \\
1.536 \pm 0.384 \\
0.696 \pm 0.174 \\
\end{array}$ & $\begin{array}{l}2.046 \pm 0.0105 \\
3.112 \pm 0.0239 \\
3.524 \pm 0.0583 \\
\end{array}$ & $\begin{array}{l}0.0068 \pm 0.0015 \\
0.0078 \pm 0.0021 \\
0.0078 \pm 0.0021 \\
\end{array}$ & $-5.312 \pm 1.666$ & $0.7678 \pm 0.1814$ & 8.29 & 0.0261 \\
\hline Fh-pH-05 & $\begin{array}{l}\mathrm{Ni}-\mathrm{O} \\
\mathrm{Ni}-\mathrm{Fe} \\
\mathrm{Ni}-\mathrm{Fe} \\
\end{array}$ & $\begin{array}{l}5.846 \pm 0.767 \\
1.457 \pm 0.364 \\
0.814 \pm 0.204 \\
\end{array}$ & $\begin{array}{l}2.046 \pm 0.0092 \\
3.103 \pm 0.0212 \\
3.567 \pm 0.0430 \\
\end{array}$ & $\begin{array}{l}0.0061 \pm 0.0013 \\
0.0076 \pm 0.0021 \\
0.0076 \pm 0.0021 \\
\end{array}$ & $-5.446 \pm 1.516$ & $0.7287 \pm 0.1532$ & 11.31 & 0.0215 \\
\hline Goe-C-06 & $\begin{array}{l}\mathrm{Ni}-\mathrm{O} \\
\mathrm{Ni}-\mathrm{Fe} \\
\end{array}$ & $\begin{array}{l}7.404 \pm 0.861 \\
1.040 \pm 0.445 \\
\end{array}$ & $\begin{array}{l}2.045 \pm 0.0092 \\
3.070 \pm 0.0277 \\
\end{array}$ & $\begin{array}{l}0.0102 \pm 0.0015 \\
0.0102 \pm 0.0015\end{array}$ & $-6.092 \pm 1.250$ & - & 3.23 & 0.0100 \\
\hline
\end{tabular}

$\mathrm{CN}$ : coordination number

$\mathrm{R}$ : interatomic distance

$\sigma^{2}$ : Debye-Waller factor

$\Delta \mathrm{E}_{0}$ : energy shift

Red $X^{2}$ : reduced chi squared statistic

$\mathrm{S}_{0}{ }^{2}: 0.96$

K-range: 3-1

R-range: $1-4$ 

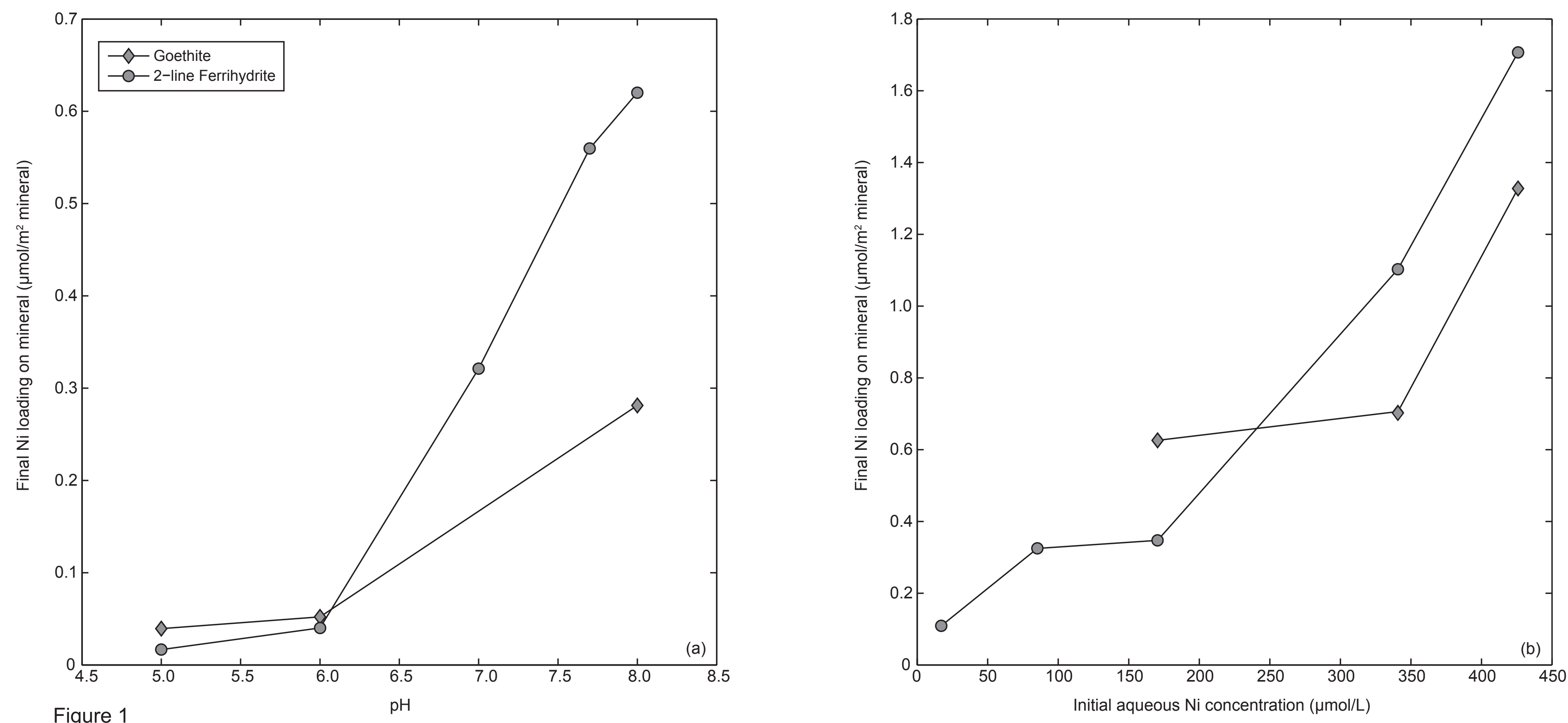
2-line ferrihydrite

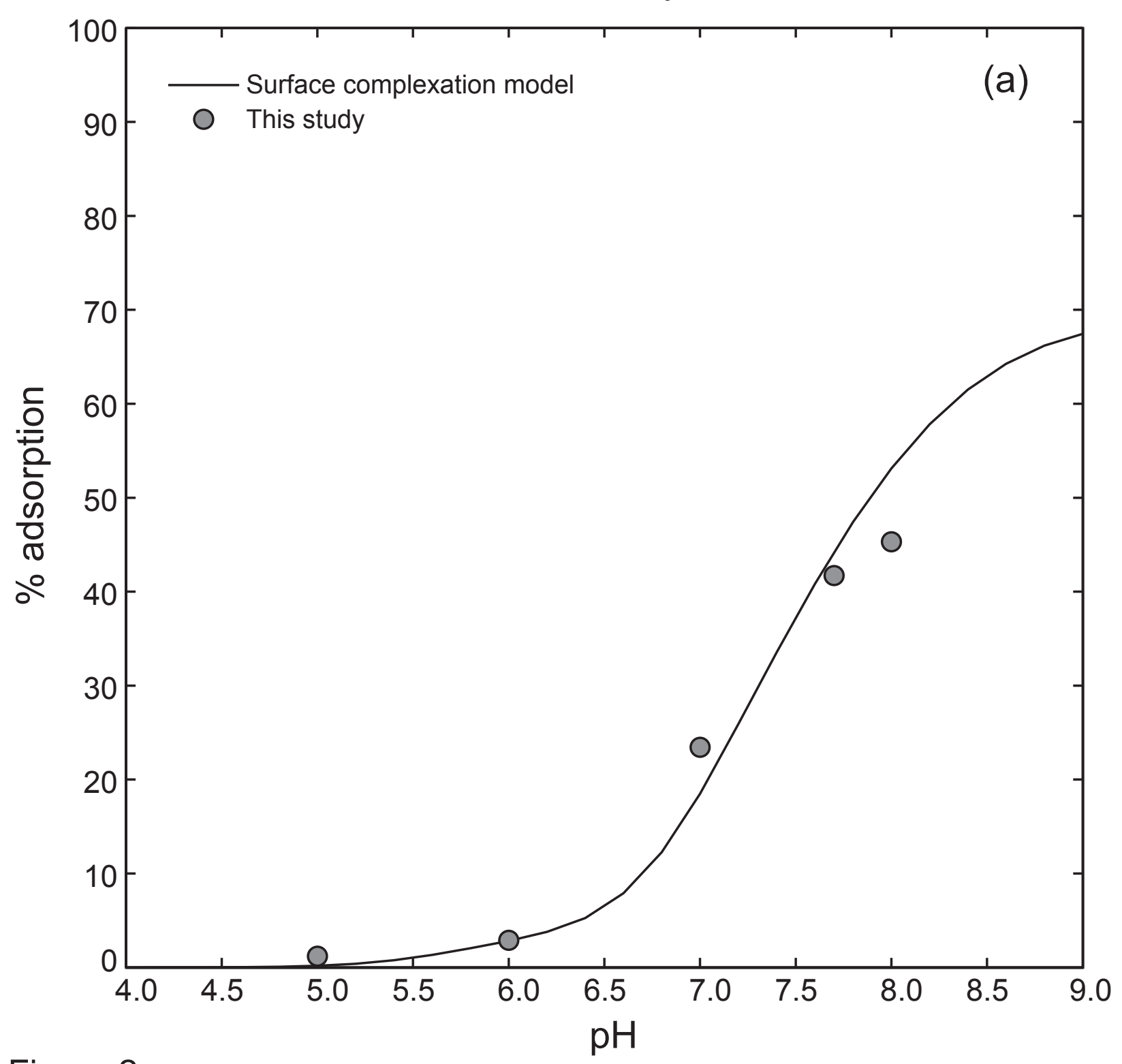

\section{Goethite}

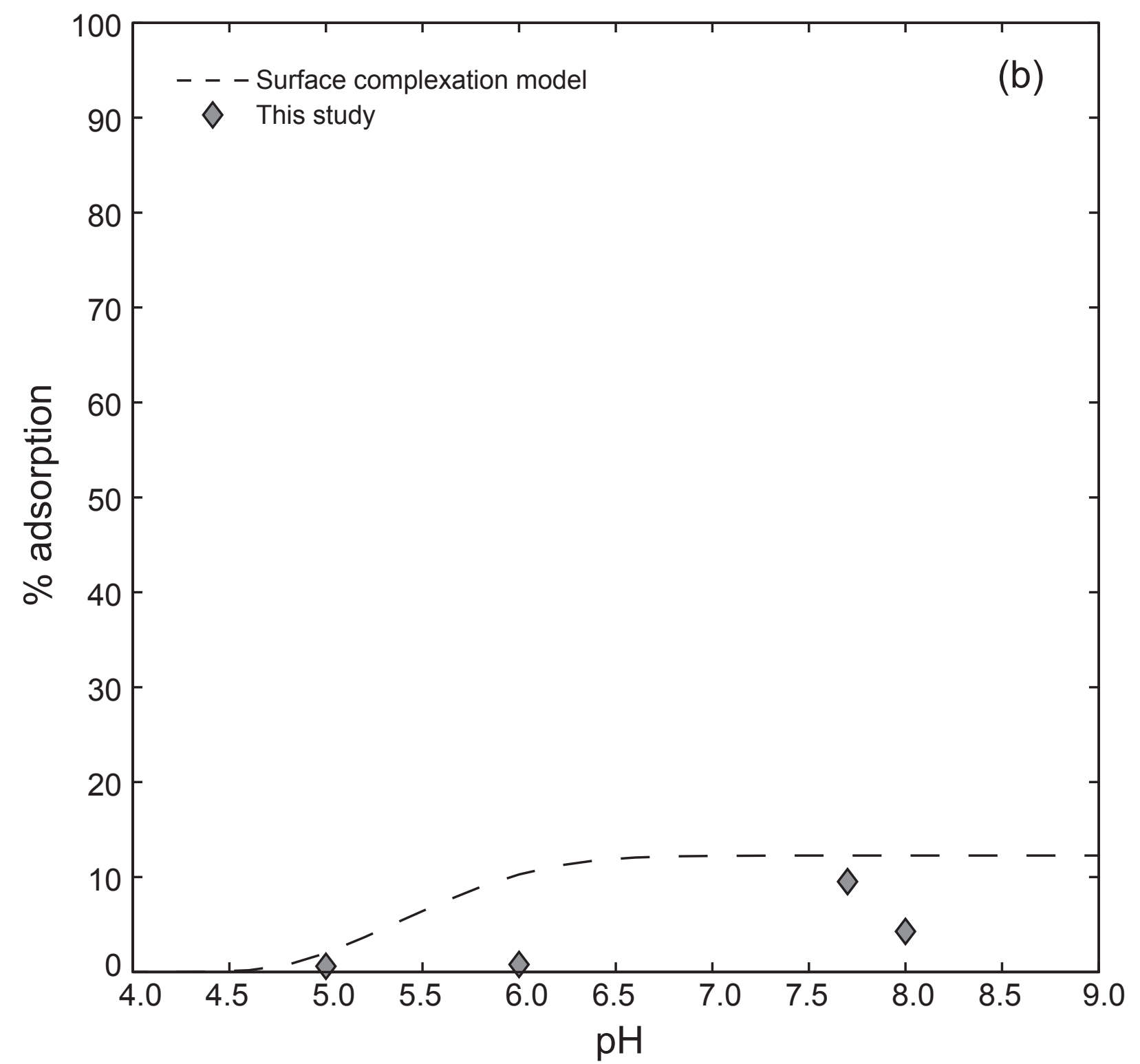

Figure 2 


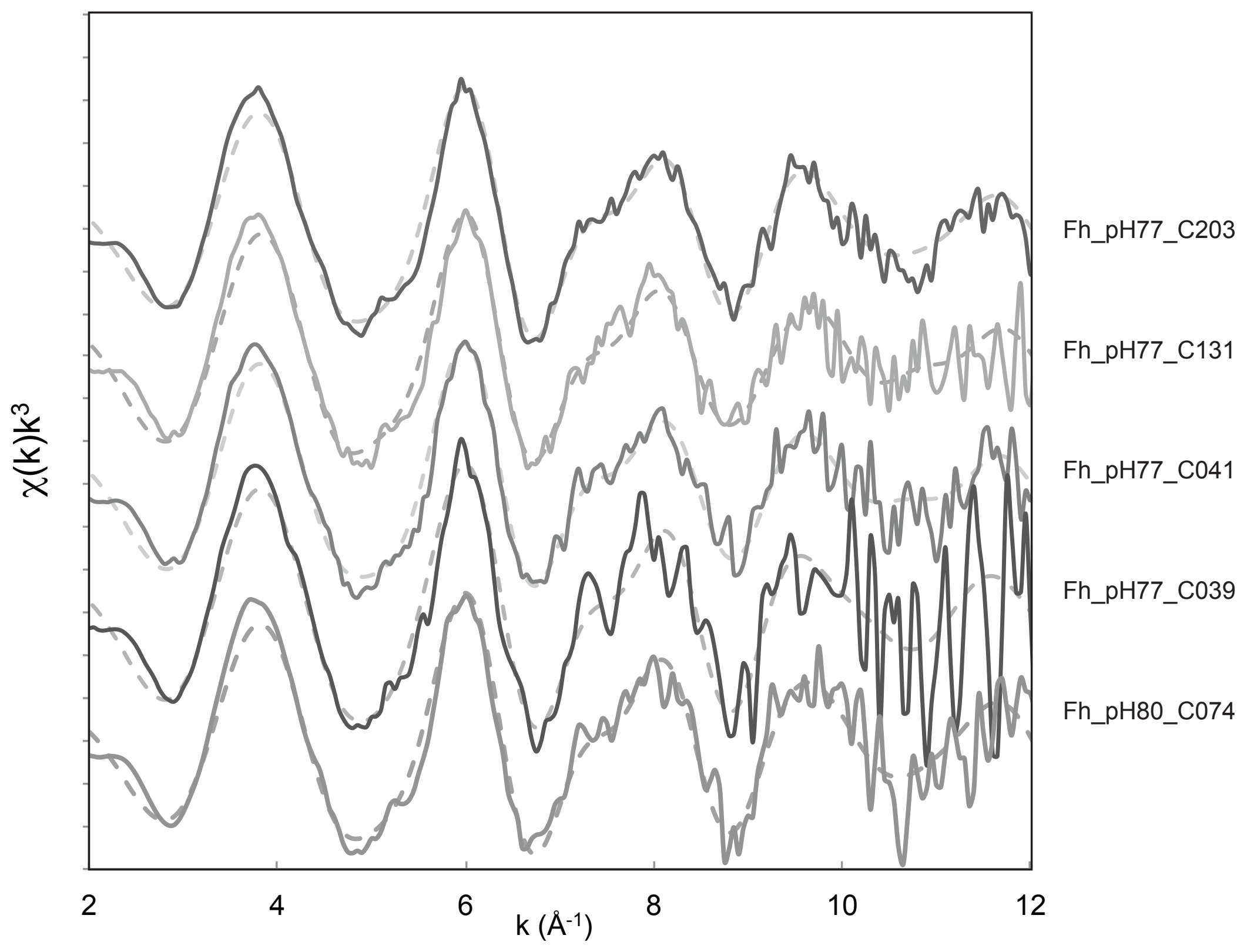

Figure 3 

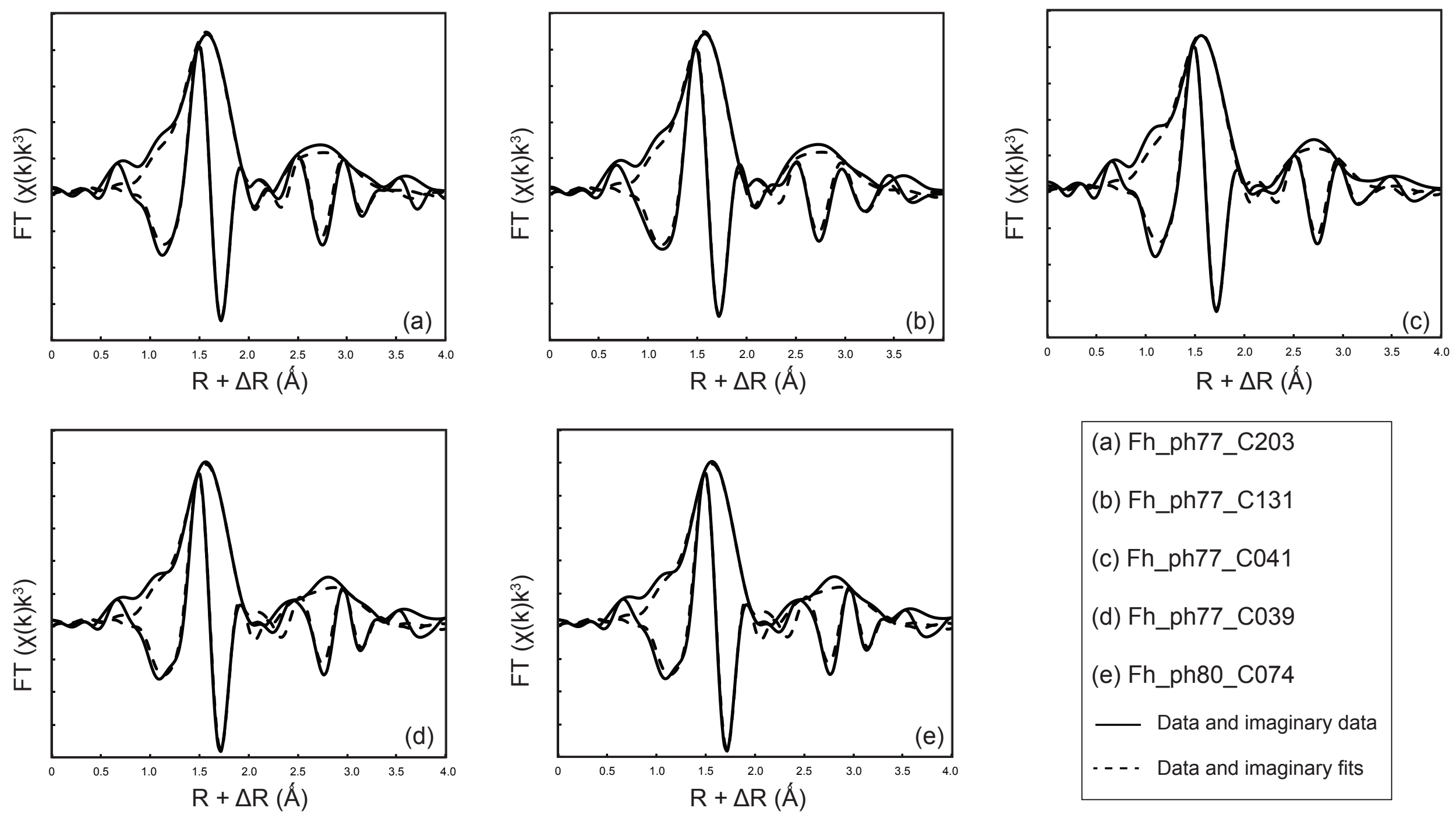
(a) Fh_ph77_C203
(b) Fh_ph77_C131
(c) Fh_ph77_C041
(d) Fh_ph77_C039
(e) Fh_ph80_C074
_ Data and imaginary data
- - - Data and imaginary fits

Figure 4 

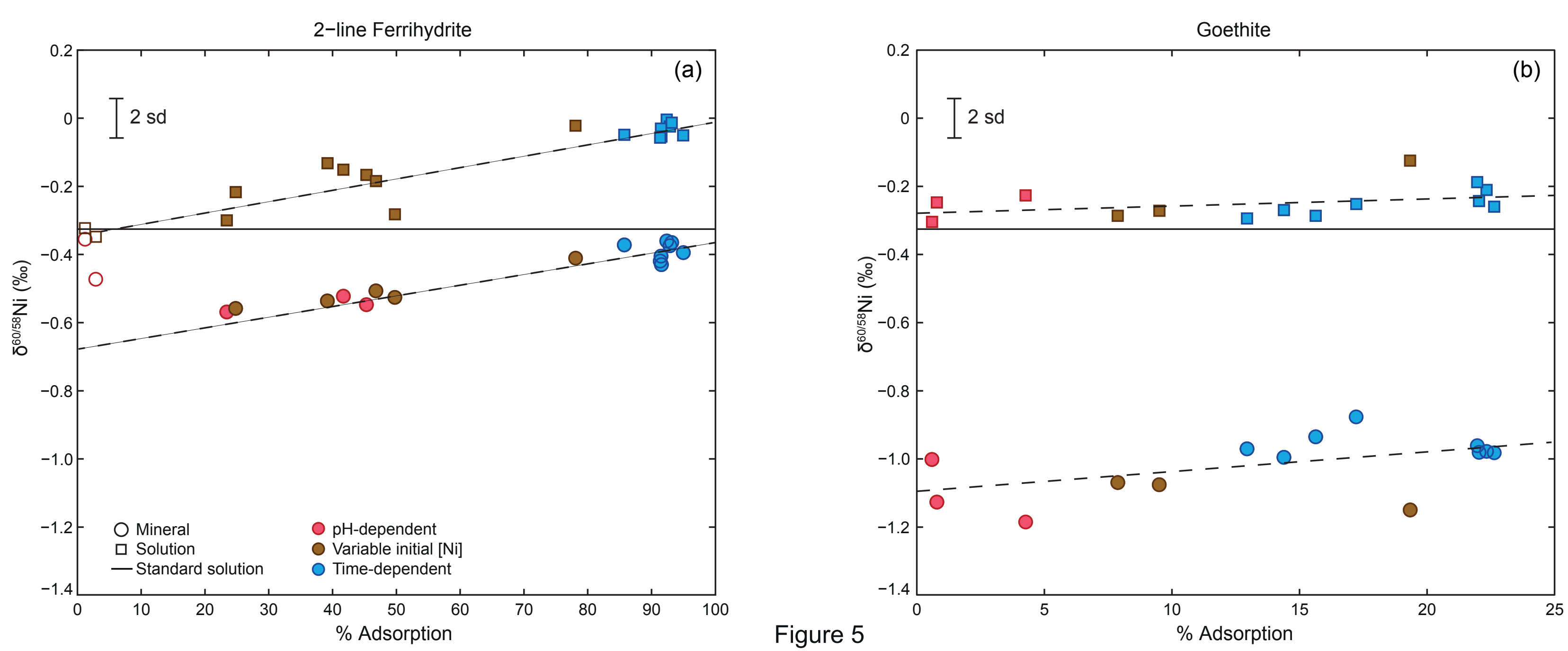

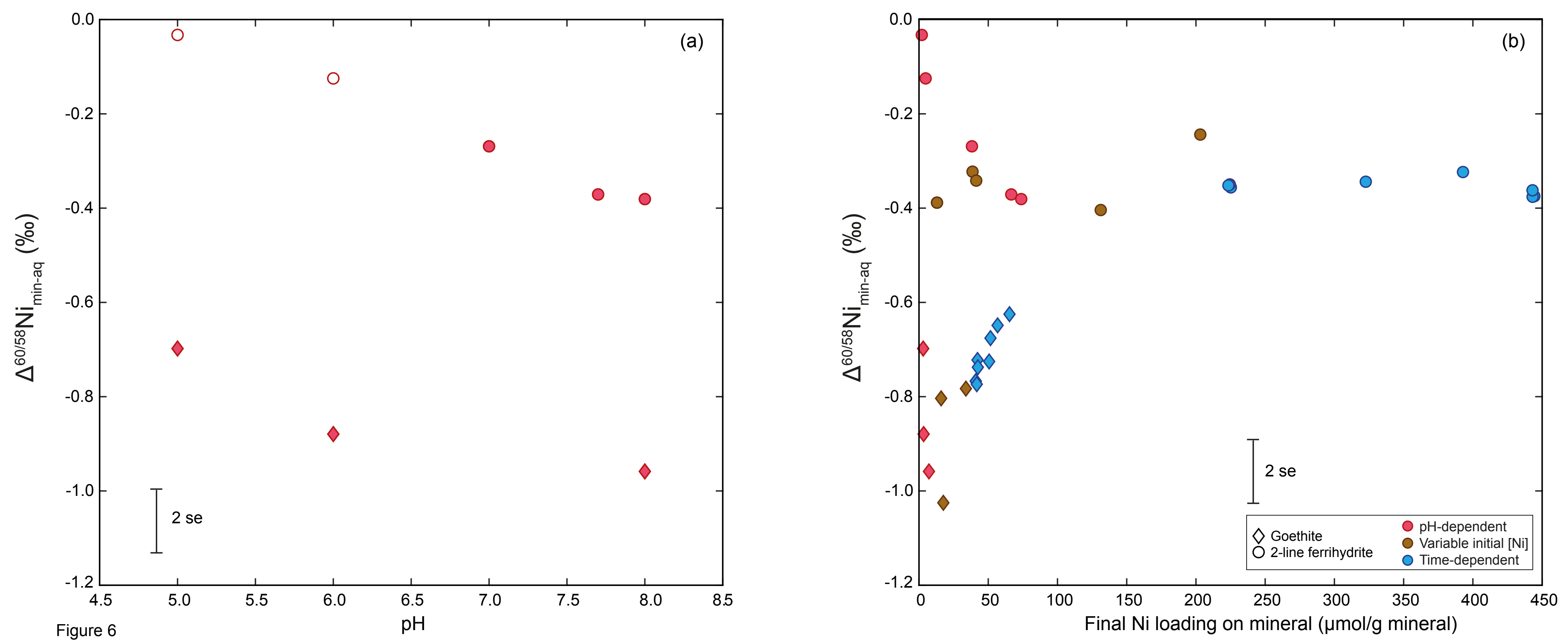

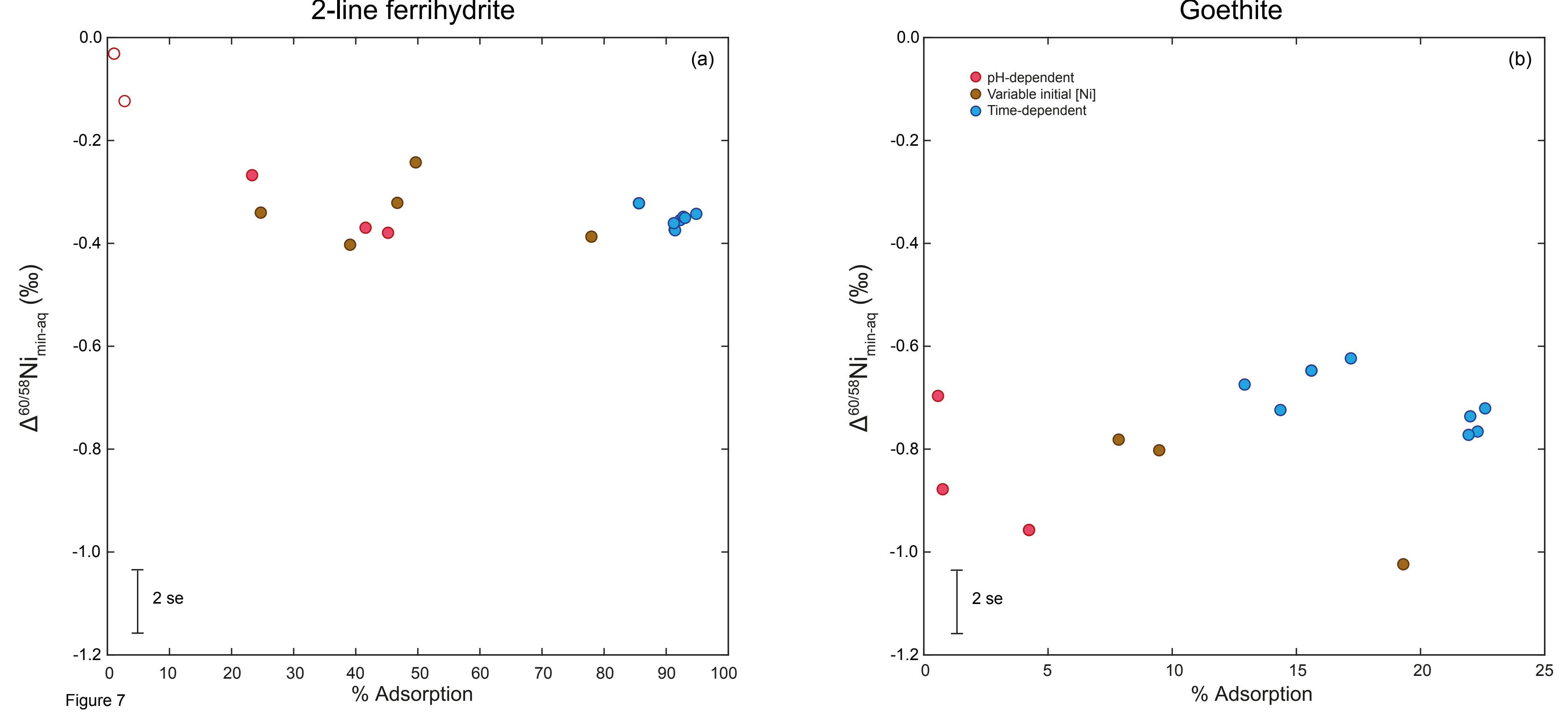


\section{Electronic Annex}

Variable Ni isotope fractionation between Fe-oxyhydroxides and implications for the use of Ni isotopes as geochemical tracers

Bleuenn Gueguen ${ }^{1,2 *}$, Jeffry V. Sorensen ${ }^{3}$, Stefan V. Lalonde ${ }^{1}$, Jasquelin Peña ${ }^{4}$, Brandy M. Toner $^{3}$, and Olivier Rouxel ${ }^{2}$

${ }^{1}$ Institut Universitaire Européen de la Mer, Laboratoire Domaines Océaniques UMR 6538, Université de Brest, 29280 Plouzané, France

2IFREMER, Centre de Brest, Unité Géosciences Marines, 29280 Plouzané, France

${ }^{3}$ Department of Soil, Water, and Climate, University of Minnesota, St. Paul, MN 55108, USA ${ }^{4}$ Institute of Earth Surface Dynamics, University of Lausanne, CH-1015 Lausanne, Switzerland

Submitted to Chemical Geology

*Corresponding author:

E-mail address: bleuenn.gueguen@univ-brest.fr

Current address: Institut Universitaire Européen de la Mer, CNRS UMS 3113, Université de Brest, 29280 Plouzané, France 


\section{Supplementary Figures :}

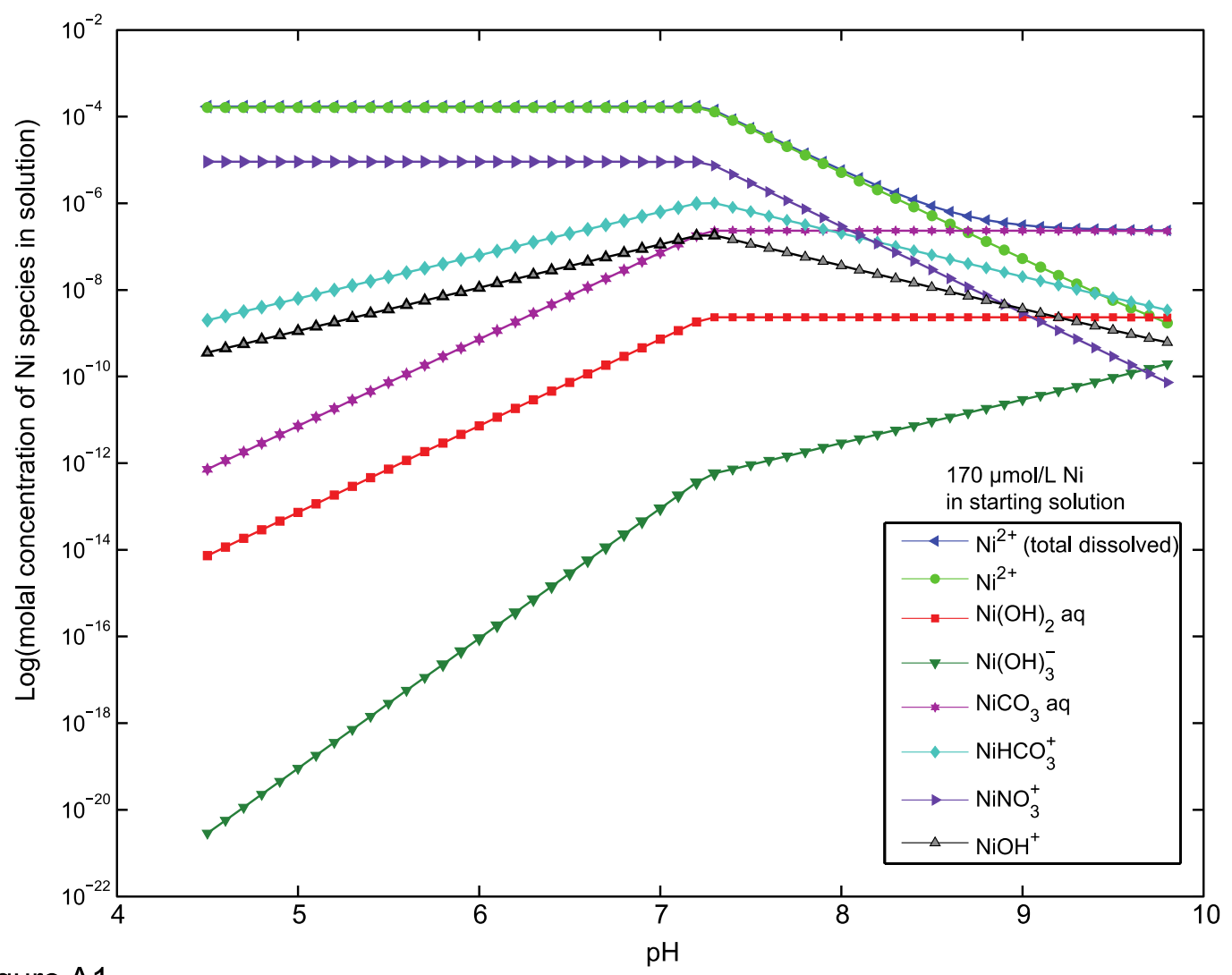

Figure A1

Figure A1: Nickel speciation modeling (logarithm of molal concentrations of different $\mathrm{Ni}$ species) versus $\mathrm{pH}$ of solution for $170 \mu \mathrm{mol} / \mathrm{L}$ of $\mathrm{Ni}$ in starting solution. The curves represent the different $\mathrm{Ni}$ species present in the system, i.e., $\mathrm{Ni}^{2+}, \mathrm{Ni}(\mathrm{OH})_{2 \mathrm{aq}}, \mathrm{Ni}(\mathrm{OH})_{3}{ }^{-}, \mathrm{NiCO}_{3 a q}$, $\mathrm{NiHCO}_{3}{ }^{+}, \mathrm{NiNO}_{3}{ }^{+}, \mathrm{NiOH}^{+}$. 
Figure A2: Cartoon showing Ni bonding environment according to a "Type 1" configuration or a "Type 2 " configuration.
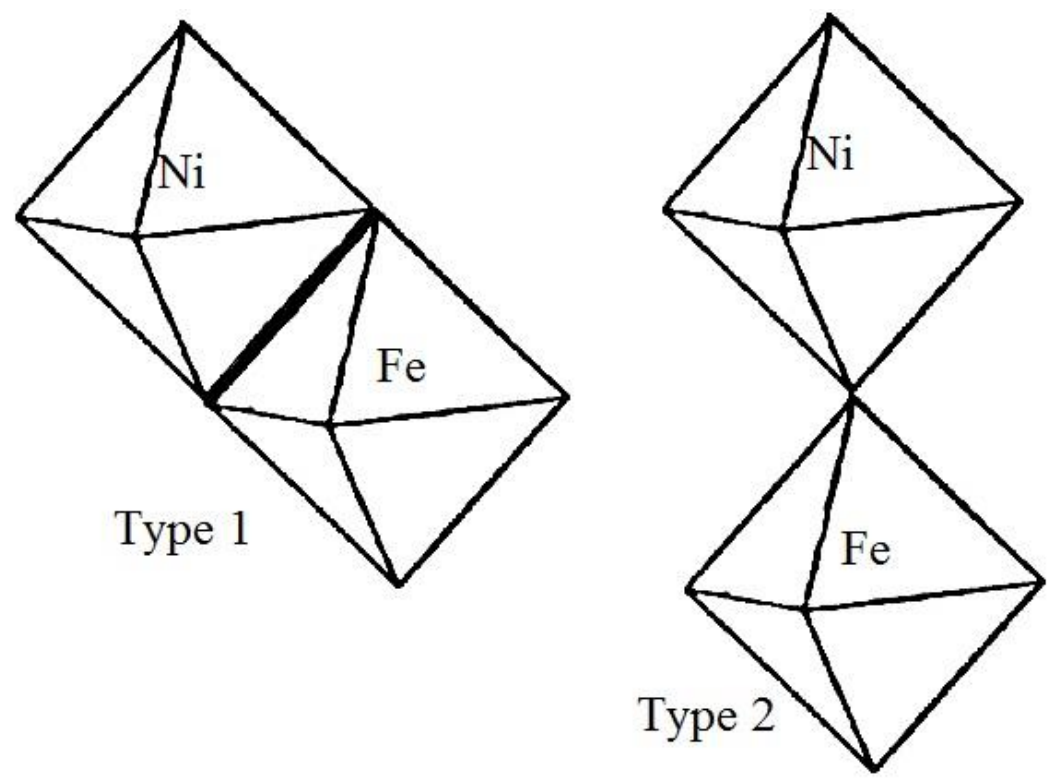

Figure A3: Nickel speciation versus $\mathrm{pH}$ of the solution for different initial $\mathrm{Ni}$ (aq), (a) 17 $\mu \mathrm{mol} \mathrm{Ni} / \mathrm{L}$, (b) $85 \mu \mathrm{mol} \mathrm{Ni} / \mathrm{L}$, (c) $170 \mu \mathrm{mol} \mathrm{Ni} / \mathrm{L}$, (d) $341 \mu \mathrm{mol} \mathrm{Ni} / \mathrm{L}$, and (e) $426 \mu \mathrm{mol} \mathrm{Ni}$ $/ \mathrm{L}$.

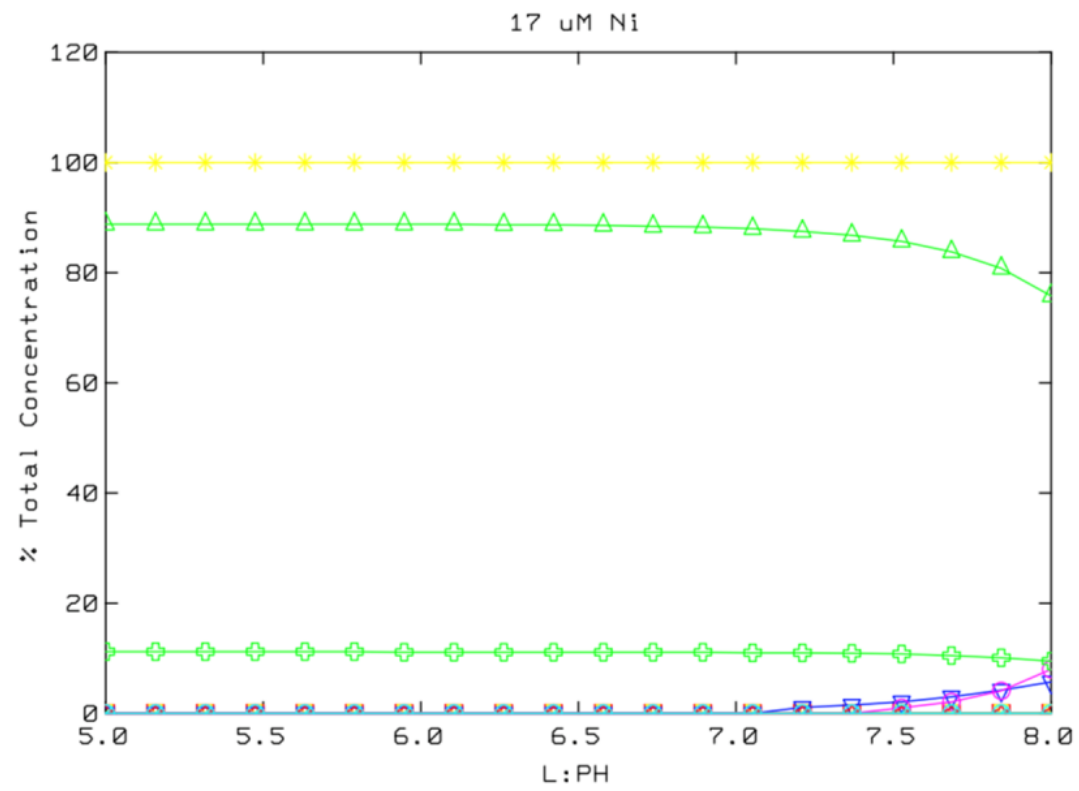

(a) 


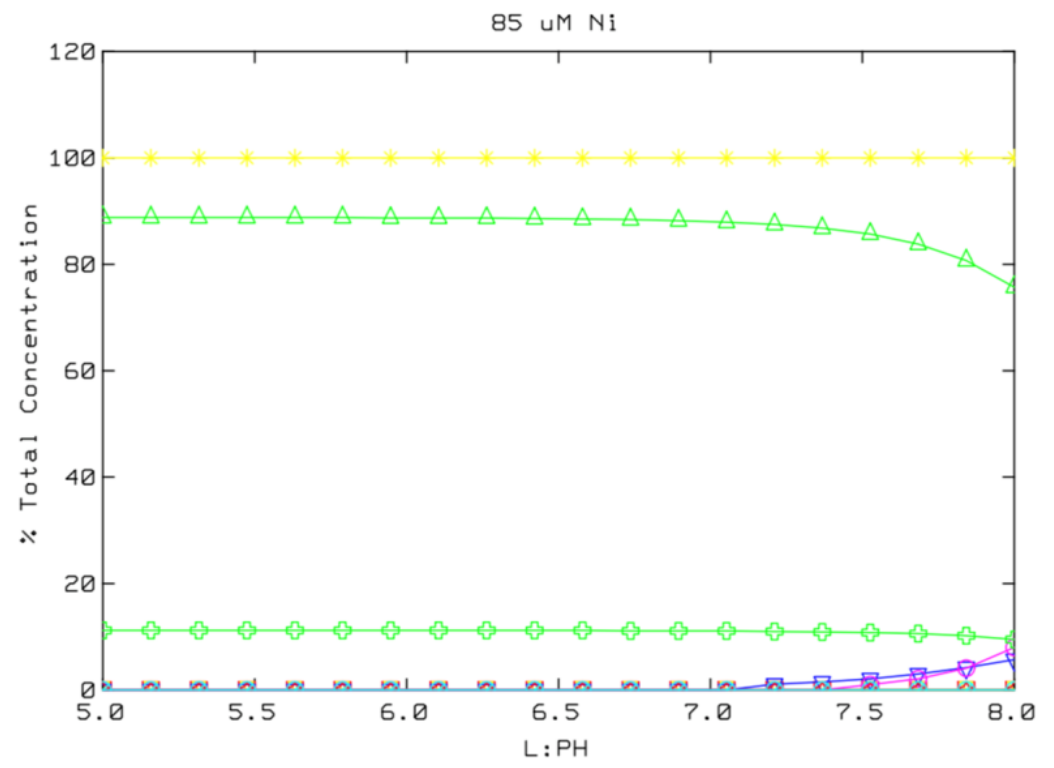

(b)

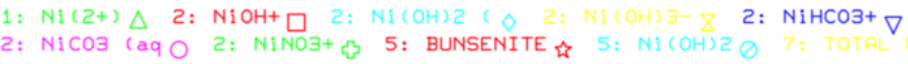

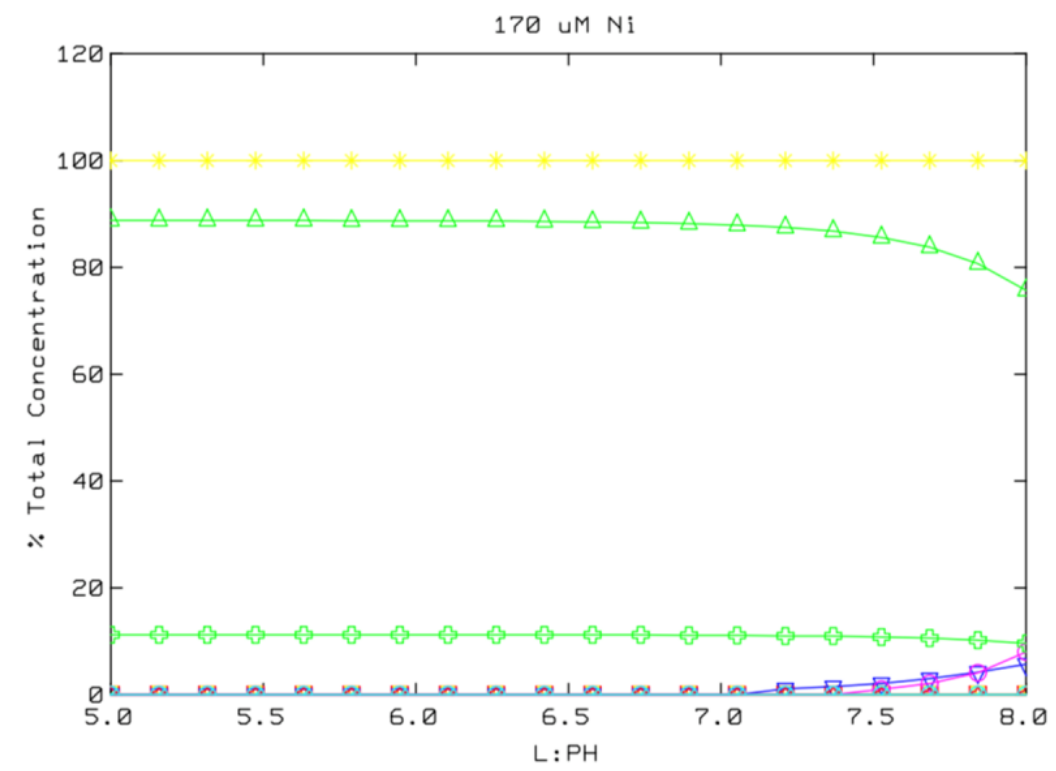

(c)

1: $\mathrm{Ni}(2+) \triangle$ 2: $\mathrm{NiOH}+\square$ 2: $\mathrm{Ni}(\mathrm{OH}) 2\left(\Delta 2: \mathrm{Ni}(\mathrm{OH}) 3^{-} \mathrm{Z}\right.$ 2: $\mathrm{NiHCO}^{+} \nabla$

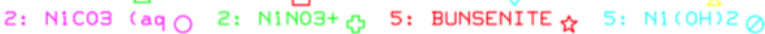




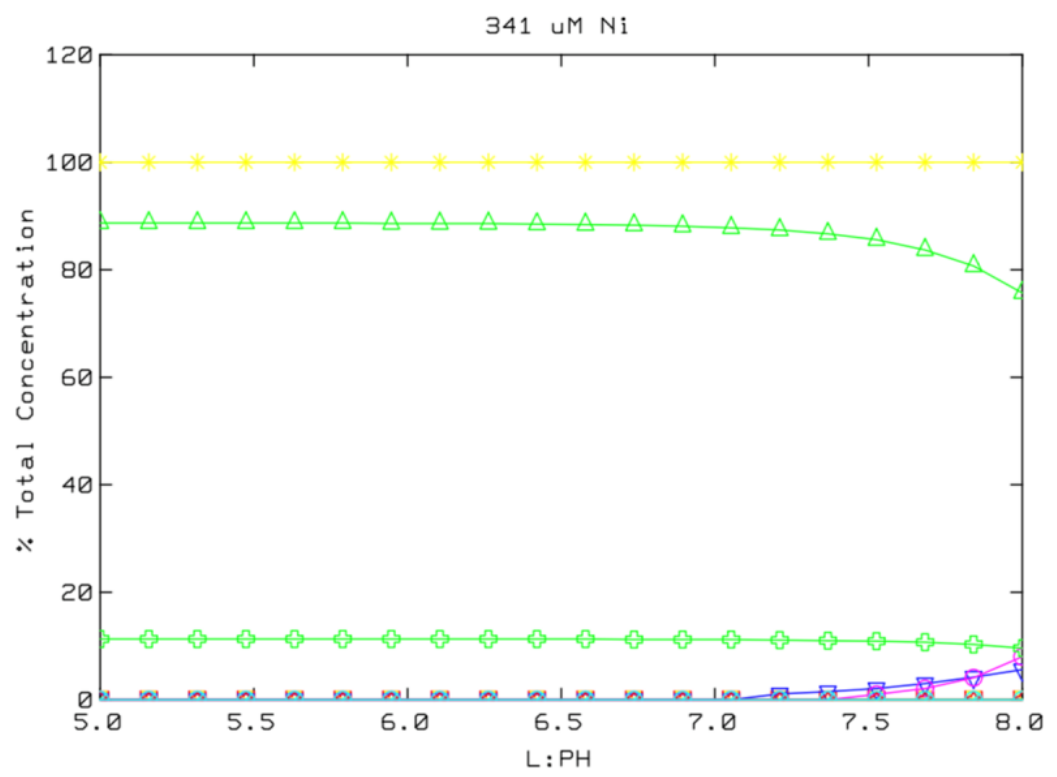

(d)

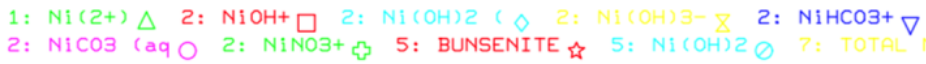

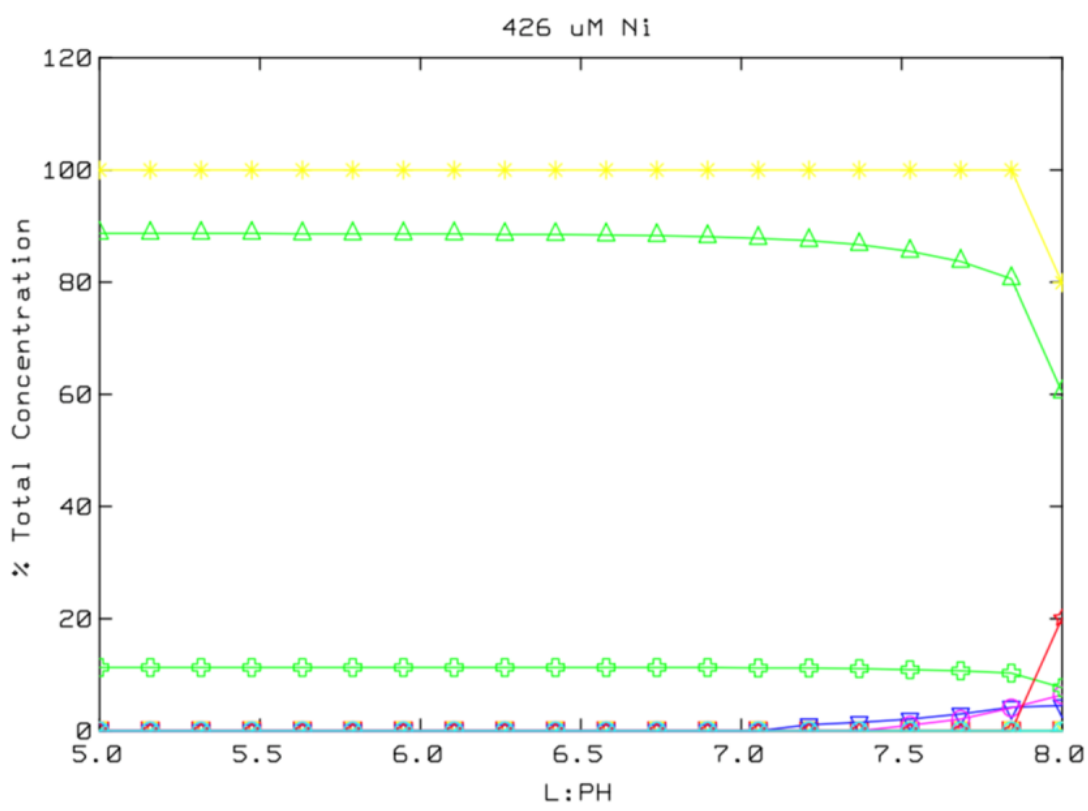

(e) 
Supplementary Tables :

Table S1: Zeta potential measurement parameters.

\begin{tabular}{|c|c|c|c|c|c|c|c|}
\hline $\begin{array}{c}\text { Mineral } \\
\text { type }\end{array}$ & $\begin{array}{c}\text { Amount of } \\
\text { mineral in } \\
\text { solution }\end{array}$ & Conductance & Current & $\begin{array}{c}\text { Applied } \\
\text { Voltage }\end{array}$ & $\begin{array}{c}\text { Zeta } \\
\text { potential }\end{array}$ & Mobility & $\begin{array}{c}\text { Relative } \\
\text { Residual }\end{array}$ \\
\hline $\begin{array}{c}\text { 2-line } \\
\text { Ferrihydrite }\end{array}$ & $1.44 \mathrm{~g} / \mathrm{L}$ & $344 \mu \mathrm{S}$ & $2.56 \mathrm{~mA}$ & $7.54 \mathrm{~V}$ & $-3.44 \mathrm{mV}$ & -0.027 & 0.0093 \\
\hline Goethite & $0.984 \mathrm{~g} / \mathrm{L}$ & $81 \mu \mathrm{S}$ & $0.712 \mathrm{~mA}$ & $7.54 \mathrm{~V}$ & $3.46 \mathrm{mV}$ & 0.27 & 0.0151 \\
\hline
\end{tabular}


Table S2: Summary of EXAFS fit parameters for previous Ni-sorption and -incorporation experiments. Data for $\mathrm{Zn}$ are shown for comparison. Literature data is from (Manceau et al., 2000; Waychunas et al., 2002; Arai, 2008; Juillot et al., 2008; Dublet et al., 2012; Cismasu et al., 2013).

\begin{tabular}{|c|c|c|c|c|c|}
\hline Sample type & Atom Pair & $\mathrm{CN}^{1}$ & $\mathbf{R}(\AA)^{2}$ & $\sigma^{2}\left(\AA^{2}\right)^{3}$ & Reference \\
\hline Ni-sorbed goethite & $\begin{array}{c}\mathrm{Ni}-\mathrm{O} \\
\mathrm{Ni}-\mathrm{Fe} \\
\mathrm{Ni}-\mathrm{Fe}\end{array}$ & $\begin{array}{l}5.1 \\
1.5 \\
2.4\end{array}$ & $\begin{array}{l}2.10 \\
3.00 \\
3.14\end{array}$ & $\begin{array}{c}0.0049 \\
0.0049 \\
-\end{array}$ & Dublet et al. 2012 \\
\hline $\mathrm{Ni}$-sorbed goethite & $\begin{array}{l}\mathrm{Ni}-\mathrm{O} \\
\mathrm{Ni}-\mathrm{Fe} \\
\mathrm{Ni}-\mathrm{Fe} \\
\mathrm{Ni}-\mathrm{Fe}\end{array}$ & $\begin{array}{l}5.7 \\
1.2 \\
1.1 \\
1.7\end{array}$ & $\begin{array}{l}2.06 \\
3.03 \\
3.18 \\
4.06 \\
\end{array}$ & $\begin{array}{l}0.0051 \\
0.0050 \\
0.0050 \\
0.0080\end{array}$ & Arai, 2008 \\
\hline Zn-sorbed goethite & $\begin{array}{l}\mathrm{Zn}-\mathrm{O} \\
\mathrm{Zn}-\mathrm{Fe} \\
\mathrm{Zn}-\mathrm{Fe}\end{array}$ & $\begin{array}{l}4.6 \\
0.9 \\
0.8 \\
\end{array}$ & $\begin{array}{l}2.06 \\
3.07 \\
3.26 \\
\end{array}$ & $\begin{array}{c}0.0081 \\
0.0081 \\
- \\
\end{array}$ & Juillot et al. 2008 \\
\hline Zn-sorbed ferrihydrite & $\begin{array}{l}\mathrm{Zn}-\mathrm{O} \\
\mathrm{Zn}-\mathrm{Fe} \\
\mathrm{Zn}-\mathrm{Fe} \\
\end{array}$ & $\begin{array}{l}3.6 \\
0.9 \\
1.9 \\
\end{array}$ & $\begin{array}{l}1.98 \\
3.21 \\
3.44 \\
\end{array}$ & $\begin{array}{c}0.006 \\
0.011 \\
0.01 \\
\end{array}$ & Cismasu et al. 2013 \\
\hline Zn-sorbed ferrihydrite & $\begin{array}{l}\mathrm{Zn}-\mathrm{O} \\
\mathrm{Zn}-\mathrm{Fe}\end{array}$ & $\begin{array}{l}5.05 \\
1.93\end{array}$ & $\begin{array}{l}1.96 \\
3.43\end{array}$ & $\begin{array}{l}0.007 \\
0.012\end{array}$ & Waychunas et al. 2002 \\
\hline Zn-sorbed ferrihydrite & $\begin{array}{l}\mathrm{Zn}-\mathrm{O} \\
\mathrm{Zn}-\mathrm{Fe}\end{array}$ & $\begin{array}{c}3.2 \\
1\end{array}$ & $\begin{array}{l}1.96 \\
3.47\end{array}$ & $\begin{array}{c}0.0049 \\
0.01\end{array}$ & Juillot et al. 2008 \\
\hline $\mathrm{Ni}$-sorbed ferrihydrite & $\begin{array}{l}\mathrm{Ni}-\mathrm{O} \\
\mathrm{Ni}-\mathrm{Fe} \\
\mathrm{Ni}-\mathrm{Fe} \\
\mathrm{Ni}-\mathrm{Fe} \\
\end{array}$ & $\begin{array}{l}5.9 \\
1.0 \\
1.8 \\
1.0 \\
\end{array}$ & $\begin{array}{l}2.05 \\
3.08 \\
3.21 \\
4.03 \\
\end{array}$ & $\begin{array}{l}0.0054 \\
0.0050 \\
0.0050 \\
0.0080 \\
\end{array}$ & Arai, 2008 \\
\hline $\mathrm{Ni}$-sorbed ferrihydrite & $\begin{array}{l}\mathrm{Ni}-\mathrm{O} \\
\mathrm{Ni}-\mathrm{Fe} \\
\mathrm{Ni}-\mathrm{Fe} \\
\mathrm{Ni}-\mathrm{Fe}\end{array}$ & $\begin{array}{l}5.7 \\
1.4 \\
1.9 \\
1.1\end{array}$ & $\begin{array}{l}2.06 \\
3.05 \\
3.21 \\
4.05 \\
\end{array}$ & $\begin{array}{l}0.0060 \\
0.0050 \\
0.0050 \\
0.0080\end{array}$ & Arai, 2008 \\
\hline $\mathrm{Ni}$-sorbed ferrihydrite & $\begin{array}{l}\mathrm{Ni}-\mathrm{O} \\
\mathrm{Ni}-\mathrm{Fe} \\
\mathrm{Ni}-\mathrm{Fe} \\
\mathrm{Ni}-\mathrm{Fe} \\
\end{array}$ & $\begin{array}{l}5.8 \\
1.5 \\
1.3 \\
0.9 \\
\end{array}$ & $\begin{array}{l}2.06 \\
3.06 \\
3.19 \\
4.07 \\
\end{array}$ & $\begin{array}{c}0.006 \\
0.0050 \\
0.0050 \\
0.0080 \\
\end{array}$ & Arai 2008 \\
\hline Ni-bearing goethite & $\begin{array}{l}\mathrm{Ni}-\mathrm{O} \\
\mathrm{Ni}-\mathrm{Fe} \\
\mathrm{Ni}-\mathrm{Fe} \\
\mathrm{Ni}-\mathrm{Fe}\end{array}$ & $\begin{array}{l}5.3 \\
2.1 \\
1.4 \\
2.5\end{array}$ & $\begin{array}{l}2.07 \\
3.00 \\
3.18 \\
3.62 \\
\end{array}$ & $\begin{array}{l}0.0036 \\
0.0064 \\
0.0064 \\
0.0064\end{array}$ & Manceau et al. 2000 \\
\hline Ni-bearing goethite & $\begin{array}{l}\mathrm{Ni}-\mathrm{O} \\
\mathrm{Ni}-\mathrm{Fe} \\
\mathrm{Ni}-\mathrm{Fe} \\
\mathrm{Ni}-\mathrm{Fe}\end{array}$ & $\begin{array}{l}5.7 \\
2.0 \\
2.0 \\
1.2\end{array}$ & $\begin{array}{l}2.05 \\
2.98 \\
3.16 \\
3.57\end{array}$ & $\begin{array}{c}0.0049 \\
0.0049 \\
- \\
-\end{array}$ & Dublet et al. 2012 \\
\hline
\end{tabular}

${ }^{1,2,3}$ See Table 2 and main text. 


\section{References :}

Arai, Y., 2008. Spectroscopic Evidence for Ni(II) Surface Speciation at the Iron Oxyhydroxides-Water Interface. Environmental Science \& Technology, 42(4): 1151-1156.

Cismasu, A.C., Levard, C., Michel, F.M., Brown Jr, G.E., 2013. Properties of impurity-bearing ferrihydrite II: Insights into the surface structure and composition of pure, Al- and Si-bearing ferrihydrite from Zn(II) sorption experiments and Zn K-edge X-ray absorption spectroscopy. Geochimica et Cosmochimica Acta, 119(0): 46-60.

Dublet, G. et al., 2012. Ni speciation in a New Caledonian lateritic regolith: A quantitative X-ray absorption spectroscopy investigation. Geochimica et Cosmochimica Acta, 95(0): 119-133.

Juillot, F. et al., 2008. Zn isotopic fractionation caused by sorption on goethite and 2-Lines ferrihydrite. Geochimica Et Cosmochimica Acta, 72(19): 4886-4900.

Manceau, A. et al., 2000. Crystal chemistry of trace elements in natural and synthetic goethite. Geochimica et Cosmochimica Acta, 64(21): 3643-3661.

Waychunas, G.A., Fuller, C.C., Davis, J.A., 2002. Surface complexation and precipitate geometry for aqueous $\mathrm{Zn}(\mathrm{II})$ sorption on ferrihydrite I: X-ray absorption extended fine structure spectroscopy analysis. Geochimica et Cosmochimica Acta, 66(7): 1119-1137. 